\title{
Anti-malarial drug: the emerging role of artemisinin and its derivatives in liver disease treatment
}

\author{
Ye Xiong and Jianrong Huang ${ }^{*}$ (D)
}

\begin{abstract}
Artemisinin and its derivatives belong to a family of drugs approved for the treatment of malaria with known clinical safety and efficacy. In addition to its anti-malarial effect, artemisinin displays anti-viral, anti-inflammatory, and anti-cancer effects in vivo and in vitro. Recently, much attention has been paid to the therapeutic role of artemisinin in liver diseases. Several studies suggest that artemisinin and its derivatives can protect the liver through different mechanisms, such as those pertaining to inflammation, proliferation, invasion, metastasis, and induction of apoptosis and autophagy. In this review, we provide a comprehensive discussion of the underlying molecular mechanisms and signaling pathways of artemisinin and its derivatives in treating liver diseases. Further pharmacological research will aid in determining whether artemisinin and its derivatives may serve as promising medicines for the treatment of liver diseases in the future.
\end{abstract}

Keywords: Artemisinin, Liver disease, Malaria, Anti-inflammatory, Apoptosis

\section{Background}

Liver diseases and their associated complications are major public health concerns and among of the most significant causes of death worldwide, owing to their progressive pathogenesis and lack of effective treatment modalities. Liver diseases include viral and non-viral hepatitis, alcoholic fatty liver disease (AFLD), non-alcoholic fatty liver disease (NAFLD), cholestatic liver diseases, autoimmune liver diseases, liver failure, liver fibrosis, and increasing end-stage liver disorders, such as cirrhosis and primary hepatic tumors, including hepatocellular carcinoma (HCC) and cholangiocarcinoma (CCA) [1-3]. As the main organ for detoxification and metabolism, the

*Correspondence: hzhuangchina@zju.edu.cn

The Department of Infectious Diseases, State Key Laboratory

for Diagnosis and Treatment of Infectious Diseases, National Clinical Research Center for Infectious Diseases, Collaborative Innovation Center for Diagnosis and Treatment of Infectious Diseases, The First Affiliated Hospital, Zhejiang University School of Medicine, 79 Qingchun Road, Hangzhou 310003, China liver is important in protecting against toxicity. However, it is also vulnerable to various threats from the environment [4]. According to the World Health Organization's (WHO) 2015 Global Health Estimates data, there were more than two million global deaths due to liver diseases in 2015, and hepatitis B virus-induced liver cirrhosis was the main cause of liver-related deaths in the Asia-Pacific region [5]. To date, NAFLD is rapidly becoming a predominant cause of liver-related morbidity and mortality worldwide [6]. However, the clinical treatment of these chronic liver diseases is complicated by numerous problems, including progressive disease courses, late detection, and limited treatment options. Once chronic liver disease progresses to decompensated liver cirrhosis and end-stage HCC, treatments become increasingly limited. Therefore, it is of great importance to explore alternative effective drugs.

Traditional Chinese herbal medicine (TCHM) has been widely used to treat various diseases for thousands of years in China and throughout the world, and the original author(s) and the source, provide a link to the Creative Commons licence, and indicate if changes were made. The images or other third party material in this article are included in the article's Creative Commons licence, unless indicated otherwise in a credit line to the material. If material is not included in the article's Creative Commons licence and your intended use is not permitted by statutory regulation or exceeds the permitted use, you will need to obtain permission directly from the copyright holder. To view a copy of this licence, visit http://creativecommons.org/licenses/by/4.0/. The Creative Commons Public Domain Dedication waiver (http://creativeco mmons.org/publicdomain/zero/1.0/) applies to the data made available in this article, unless otherwise stated in a credit line to the data. 
efficacies of many treatments have been verified by modern science [7]. For example, herbal compounds such as curcumin, berberine, artemisinin, and Honeysucklederived microRNA have been verified to display anti-cancer activities through different molecular mechanisms [8, 9]. Additionally, a study showed that TCHM treatments played a positive role against the novel coronavirus disease (COVID-19), a worldwide pandemic caused by the virus SARS-CoV-2 [10]. The TCHM-based medication Cerebralcare Granule ${ }^{\circledR}$, containing diverse active ingredients (such as Angelica sinensis, Chuanxiong Rhizoma, Radix Paeoniae Alba, etc.), performed well in the treatment of cognitive dysfunction, and Jinqi Jiangtang, a TCHM prescription composed of coptidis rhizoma, astragail radix, and lonicerae japonicae flos extracts, was beneficial for type 2 diabetes treatment $[11,12]$. Increasing evidence shows that some TCHM prescriptions and single herb medicines play a prospective role in treating liver diseases. Silymarin, a flavonoid antioxidant derived from the plant Silybum marianum showed promise as a treatment for chronic liver diseases [13]. The Fufang Biejia Ruangan pill, the first clinically approved herbal anti-fibrosis formula in China, has been shown to prevent tumors in mice [14]. However, it was reported that ingesting traditional and herbal medicines was a major cause of drug-induced liver injury in South Korea over a 2-year period across 17 hospitals [15]. Further research should be conducted to discover effective treatments without harmful effects.

Artemisinin, or qinghaosu, is a sesquiterpene trioxane lactone with a peroxide bridge [16]. It is derived from Artemisia annua $L$., an herb which has been used for the treatment of fevers and chills for more than a thousand years [17]. In the 1950s, the increasing resistance of Plasmodium falciparum to existing antimalarial drugs led scientists in various countries to research for better therapeutic approaches against malaria. Chinese researchers turned to an investigation of traditional medicines, and found that Artemisia annua L. exhibited a strong inhibitory effect against $P$. falciparum[18]. Inspired by the ancient book Ge Hong zhou hou bei ji fang (Prescriptions for Emergencies), they extracted the plant's active component and were able to provide artemisinin to countries devastated by malaria [19]. Youyou Tu from the China Academy of Traditional Chinese Medicine even one the 2015 Nobel Prize in Medicine for the discovery [18].

However, with continued research, artemisinin was found to be poorly soluble in both oil and water and to exhibit a short plasma half-life, limiting its therapeutic value [20]. Dihydroartemisinin (DHA) was developed a first-generation derivative by modifying the carbonyl groups into hydroxyl groups [21]. It is a more effective and stable antimalarial drug than artemisinin. Similarly, converting DHA into methyl and ethyl ether produced the more oil-soluble artemether (ARM) and arteether (ARE), respectively [22]. The smaller molecule artesunate (ART) was developed as a more water-soluble hemisuccinate derivative. Compared to artemisinin, these derivatives are more effective and easier to produce [21]. Recently, new derivatives (SM1044, SM905, SM934, and AM735) [23] have been developed, bringing interesting possibilities for future research. Detailed information regarding artemisinin and its derivatives is shown in Table 1 [24-32].

Through extensive research on artemisinin, researchers revealed that its primary anti-malarial activity is due to special internal structures called endoperoxide linkages (peroxide bridges) [33]. When the malaria parasites invade the human body, they digest a large amount of hemoglobin in host erythrocytes to obtain the nutrients necessary for growth and maturation. Hemoglobin digestion releases abundant heme and free ferrous iron. This heme and iron activate artemisinin, cleaving the peroxide bridge and producing free radicals that alkylate malaria membrane-associated proteins and impair mitochondria functions, as well as reactive oxygen species (ROS), which induce parasite damage and eventual death [20, 34-37]. A study also found that deoxyartemisinin, a substance lacking peroxide bridges, cannot induce the above process $[22,38]$, verifying that the endoperoxide linkages in artemisinin are vital to its efficacy.

In recent years, numerous studies showed that artemisinin and its derivatives also play a significant role in treating other diseases, apart from malaria. Artemisinin regulates inflammation and apoptosis, which, together with antioxidant effects, supports an argument for the use of artemisinin in different pathologies. ART inhibits human cytomegalovirus infection by antagonizing nuclear factor kappaB (NF- $\mathrm{kB}$ ) and downstream activities of AKT1 and p70S6K [39]. DHA may be used to treat systematic lupus erythematosus-related nephritis by blocking the NF- $\mathrm{kB}$ signaling pathway, increasing tumor necrosis factor- $\alpha$ (TNF- $\alpha$ ) secretion, and reducing the production of anti-ds-DNA antibodies [37]. Research has also reported that ART regulates glucose levels [40, 41].

Recently, a growing number of TCHM treatments and their active ingredients have been discovered to have hepatoprotective properties [42-45]. Most of them, however, are toxic to some extent, and the underlying molecular mechanisms and refining technologies remain poorly understood. Artemisinin is thought to have be one of these hepatoprotective treatments has been widely used in ancient times to reduce fever and eliminate jaundice and hepatitis [46]. Because artemisinin has consistently been considered safe and effective in clinical practice and was officially recommended by WHO in the 
Table 1 Characteristics of artemisinin and its derivatives

\begin{tabular}{|c|c|c|c|c|c|c|c|c|c|}
\hline Derivatives & $\begin{array}{l}\text { Molecular } \\
\text { formulas }\end{array}$ & $\begin{array}{l}\text { Chemical } \\
\text { structures }\end{array}$ & $\begin{array}{l}\text { Structural } \\
\text { modifications }\end{array}$ & $\begin{array}{l}\text { Physical } \\
\text { properties }\end{array}$ & Formulations & $\begin{array}{l}\text { Route of } \\
\text { administration }\end{array}$ & Pharmacokinetics & $\begin{array}{l}\text { Pharmacological } \\
\text { activities }\end{array}$ & Ref \\
\hline Artemisinin & $\mathrm{C}_{15} \mathrm{H}_{22} \mathrm{O}_{5}$ & & 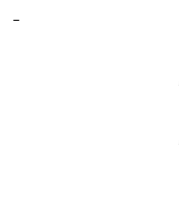 & $\begin{array}{l}\text { Poorly soluble in } \\
\text { water and oil; } \\
\text { Melting point } \\
156-157^{\circ} \mathrm{C} ; \\
\text { Molecular weightC } \\
282.35\end{array}$ & $\begin{array}{l}\text { Powder; } \\
\text { Micronized } \\
\quad \text { powder; } \\
\text { Tablet; } \\
\text { Capsule; } \\
\text { Suppository }\end{array}$ & $\begin{array}{l}\text { Oral } \\
\text { Intramuscular } \\
\text { injection } \\
\text { Rectal }\end{array}$ & $\begin{array}{l}\mathrm{T}_{\max } 1-3 \mathrm{~h} \\
\text { Volume of distribution } \\
\quad 1420-1560 \mathrm{~L} \\
\text { Clearance } 445-479 \mathrm{~L} / \mathrm{h} \\
\mathrm{T}_{1 / 2} 2.27-2.29 \mathrm{~h} \\
\mathrm{~T}_{\max } 3.4 \mathrm{~h} \\
\mathrm{~T}_{\max } 5.6 \mathrm{~h}\end{array}$ & $\begin{array}{l}\text { Antimalaria; } \\
\quad \text { Antivirus; } \\
\text { Antihelminth; } \\
\text { Anticancer; } \\
\text { Antiinflammation; }\end{array}$ & $\begin{array}{c}{[24-26,} \\
31, \\
32]\end{array}$ \\
\hline $\mathrm{DHA}$ & $\mathrm{C}_{15} \mathrm{H}_{24} \mathrm{O}_{5}$ & & $\begin{array}{l}\text { Modifying car- } \\
\text { bonyl groups } \\
\text { into } \\
\text { hydroxyl groups; } \\
\text { The active } \\
\text { metabolite of } \\
\text { all artemisinins }\end{array}$ & $\begin{array}{l}\text { Molecular weight } \\
284.4\end{array}$ & $\begin{array}{l}\text { Powder; } \\
\text { Tablet; }\end{array}$ & $\begin{array}{l}\text { Oral } \\
\text { Intramuscular } \\
\text { injection } \\
\text { Rectal }\end{array}$ & $\begin{array}{l}\mathrm{T}_{\max } 0.9-1.6 \mathrm{~h} \\
- \\
\mathrm{T}_{\max } 4 \mathrm{~h}\end{array}$ & $\begin{array}{l}\text { Antimalaria; } \\
\text { Anticancer; }\end{array}$ & $\begin{array}{c}{[24,26,} \\
28 \\
29 \\
32]\end{array}$ \\
\hline ART & $\mathrm{C}_{19} \mathrm{H}_{28} \mathrm{O}_{8}$ & & $\begin{array}{l}\text { Hemisuccinate } \\
\text { derivative of } \\
\text { DHA }\end{array}$ & $\begin{array}{l}\text { Water-soluble; } \\
\text { Molecular weight } \\
384.4\end{array}$ & $\begin{array}{l}\text { Powder } \\
\text { tSuppository } \\
\text { Tablet } \\
\text { Injection }\end{array}$ & $\begin{array}{l}\text { Oral } \\
\text { Intramuscular } \\
\quad \text { injection } \\
\text { Rectal } \\
\text { Intravenous admin- } \\
\quad \text { istration }\end{array}$ & $\begin{array}{l}\text { Bioavailability } 61 \%-88 \% \\
\mathrm{~T}_{\text {max }} 15-39 \text { min } \\
\text { Volume of distribution } \\
\quad 14.8 \mathrm{~L} / \mathrm{kg} \\
\text {-Clearance } 20.6 \mathrm{~L} / \mathrm{kg} / \mathrm{hr} \\
\mathrm{T}_{1 / 2} 0.36-1.2 \mathrm{~h} \\
\text { Bioavailability } 86.4-88 \% \\
\mathrm{~T}_{\text {max }} 7.2-12 \mathrm{~min} \\
\mathrm{~T}_{1 / 2} 25.2-48.2 \mathrm{~h} \\
\text { Clearance } 2.4-3.48 \mathrm{~L} / \mathrm{kg} / \mathrm{hr} \\
\text { Volume of distribution } \\
\quad 1.09-3.98 \mathrm{~L} / \mathrm{kg} \\
\text { Bioavailability } 54.9 \% \\
\mathrm{~T}_{\text {max }} 0.58-1.43 \mathrm{~h} \\
\mathrm{~T}_{1 / 2} 0.9-0.95 \mathrm{~h} \\
\text { Clearance } 2-3 \mathrm{~L} / \mathrm{kg} / \mathrm{hr} \\
\text { Volume of distribution } \\
\text { 0.1-0.3L/ } \mathrm{kg}\end{array}$ & $\begin{array}{l}\text { Antimalaria; } \\
\text { Antiparasite; } \\
\text { Antitumor; } \\
\text { Antivirus; } \\
\text { Antiinflammation; } \\
\text { Antibacterial }\end{array}$ & $\begin{array}{c}{[24,27,} \\
30- \\
32]\end{array}$ \\
\hline ARM & $\mathrm{C}_{16} \mathrm{H}_{26} \mathrm{O}_{5}$ & & $\begin{array}{l}\text { Production } \\
\text { methyl ether } \\
\text { from DHA }\end{array}$ & $\begin{array}{l}\text { Oil-soluble; } \\
\text { Molecular weightl } \\
298.4\end{array}$ & $\begin{array}{l}\text { Powder } \\
\text { tnjection } \\
\text { Capsule }\end{array}$ & $\begin{array}{l}\text { Oral } \\
\text { Intramuscular } \\
\text { injection } \\
\text { Rectal }\end{array}$ & $\begin{array}{l}\mathrm{T}_{\max } 1.7-6 \mathrm{~h} \\
\mathrm{~T}_{\max } 1.3-8.7 \mathrm{~h} \\
\mathrm{~T}_{\max } 3.1 \mathrm{~h}\end{array}$ & Antimalaria & $\begin{array}{c}{[24,31,} \\
32]\end{array}$ \\
\hline ARE & $\mathrm{C}_{17} \mathrm{H}_{28} \mathrm{O}_{5}$ & & $\begin{array}{l}\text { Production } \\
\beta \text {-ethyl ether } \\
\text { from DHA }\end{array}$ & $\begin{array}{l}\text { Oil-soluble; } \\
\text { Practically insolu- } \\
\quad \text { ble in water; } \\
\text { Molecular weight } \\
312.4\end{array}$ & $\begin{array}{l}\text { Powder } \\
\text { Injection }\end{array}$ & $\begin{array}{l}\text { Oral } \\
\text { Intramuscular } \\
\text { injection } \\
\text { Rectal }\end{array}$ & $\begin{array}{l}- \\
\mathrm{T}_{\max } 4.8-7 \mathrm{~h}\end{array}$ & Antimalaria & $\begin{array}{c}{[24,31,} \\
32]\end{array}$ \\
\hline
\end{tabular}

$T_{\max }$ Time to maximal concentration, $T_{1 / 2}$ Elimination half-life

1980s, it is likely among the less toxic TCHM treatments with hepatoprotective effects [47]. This applies to artemisinin derivatives as well, with one study showing that an oral dose of 2.2-3.9 mg/kg/d ART (add-on oncological therapy) is safe and well tolerated by subjects with metastatic breast cancer, without altering kidney function, liver function, or routine blood tests [48]. As opposed to other TCHM treatments with unclear hepatoprotective mechanisms, artemisinin and its derivatives are known to protect the liver through antioxidant, anti-inflammatory, pro-apoptotic, and carcinostatic mechanisms. The structure of endoperoxide linkage and production of ROS is not only regarded as a vital feature for antimalarial treatment, but is also key to liver protection [49]. Therefore, artemisinin deserves further examination to determine its clinical usage. Although artemisinin may play a promising role in liver disease treatment, no review has been conducted to systematically clarify the potential use and mechanism of artemisinin and its derivatives in the treatment of liver diseases. 
This review serves to discuss the hepatoprotective effects of artemisinin and its derivatives, ART, DHA, $\mathrm{ARM}$, and ARE, in vitro and in vivo.

\section{Pharmacological effects of artemisinin and its derivatives in vitro}

\section{Inducing cell cycle arrest}

Emerging evidence has indicated that artemisinin and its derivatives induce cell cycle arrest at different phases in HCC and non-HCC cells. Zhang and colleagues demonstrated that all three types of HCC cells, HepG2, PLC/ $\mathrm{PRF} / 5$, and Hep3B cells, were apparently arrested in the G2/M phase following DHA treatment, with reduction in the levels of cyclin $\mathrm{B}$ and cell division cycle 25 homolog C (CDC25C), and induction of p21 [50]. Similarly, ART and DHA induced both p53 wild-type (HepG2) and p53 null (Hep3B) cell G1-phase cell cycle arrest. This process was mediated by increased Cip1/p21 and Kip1/p27 protein expression, with significant decreases in E2F transcription factor 1 (E2F1), cyclin-dependent kinase (CDK) 2, CDK3, cyclin D1, and cyclin E [51]. On the contrary, DHA dose-dependently downregulated the expression of cyclin A and CDK2, and increased p53 and p21 expression in hepatic stellate cells (HSCs). Treatment with DHA for $24 \mathrm{~h}$ induced S-phase accumulation in HSCs [52]. A relatively lower dose of ART significantly inhibited the proliferation of normal rat liver BRL-3A and mouse liver AML12 cells by inducing cell cycle arrest at the G0/G1 phase, with corresponding downregulation of CDK4, cyclin D1, CDK2, and cyclin E1 expression [53]. Together, these studies suggest that artemisinins induce cell cycle arrest not only in HCC cells, but in normal, healthy liver cells. Thus, although previous research indicates that artemisinins can restrain the growth of tumor cells by blocking the cell cycle, more attention should be paid to the possible adverse effects of artemisinin-based drugs on healthy normal cells when developing therapies.

\section{Inhibition of hepatic oxidative stress and inflammation}

Some studies reported that artemisinins exert antiinflammatory effects in vitro. During plating of HSCs exposed to platelet derived growth factor (PDGF)-BB in vitro, we observed that PDGF-BB induced the production of NLR family pyrin domain containing 3 (NLRP3), pro-interleukin (IL)-1 $\beta$, pro-IL-4, pro-IL-18, interferon (IFN)- $\gamma$, and IL-1 $\beta$. Treatment with DHA inhibited the expression of pro-inflammatory factors in a dosedependent manner [54].

\section{Inhibition of cell proliferation}

The anti-proliferation effects of artemisinin and its derivatives are mostly observed in HCC cell lines. DHA inhibited the proliferation of human HCC cells (HepG2215 cells) in a dose- and time-dependent manner [55], and 24-h treatment yielded obvious inhibitory effects [56]. DHA also played a significant role in inhibiting the proliferation of HUCCT-1 and FRH201 cells. The inhibitory effect began after $12 \mathrm{~h}$, suggesting a time-dependent mechanism of action [57]. Similarly, DHA reportedly inhibited the proliferation of HepG2 cell lines by inducing the intracellular production of ROS and $\left[\mathrm{Ca}^{2+}\right][58]$. The proliferation of HCCLM6 cells was effectively inhibited after DHA treatment for $48 \mathrm{~h}$ [59]. By evaluating the anti-proliferative activity of ART, we concluded that it significantly reduced the clonogenic ability of HCCLM3 and MHCC97H cells in a dose-dependent manner [60]. Moreover, artemisinin and its derivatives displayed antiproliferative activity in HepG2 and SK-HEP-1 cells. However, the anti-proliferative effects differed across different derivatives. Interestingly, 10-dihydroartemisinyl 2'-propylpentanoate exerted stronger anti-proliferative effects on the two cell lines assayed, and this effect was five-fold more potent than that of sorafenib [61, 62].

Further, the anti-proliferative effects of artemisinin and its derivatives not only occur in cancer cells, but also in non-cancer cells. ART strongly inhibited proliferation of activated rat primary HSCs and LX-2 cells in a dose- and time-dependent manner in vitro $[63,64]$.

\section{Apoptosis induction}

The apoptotic effects of artemisinin and its derivatives are clearly observed in HCC cell lines. ART affected the progression of apoptosis in LX-2 cells, and ART treatment reduced $\mathrm{B}$-cell lymphoma $(\mathrm{Bcl}) 2$ expression and increased the bcl-2-associated $\mathrm{X}(\mathrm{Bax}) / \mathrm{Bcl}-2$ ratio in a dose-dependent manner [64]. Another study demonstrated that ART increased p53 at both the mRNA and protein levels, inducing apoptosis in rat primary HSCs [63]. Artemisinin induced apoptosis in SMMC-7721 cells in a time- and dose-dependent manner [65]. ART and DHA induced apoptosis in HepG2 and Hep3B cells. Lv et al.showed that treating HepG2 and Hep3B with ART and DHA induced an increase in the expression of Bax protein and a decrease in the expression of Bcl-2 [51]. The increased $\mathrm{Bax} / \mathrm{Bcl}-2$ ratio promoted cytochrome $\mathrm{c}$ to enter the cytosol and combine with apoptotic protease activating factor-1 (Apaf-1), activating caspase-3 and poly ADP-ribose polymerase (PARP). Furthermore, the study also demonstrated that treatment of HepG2 cells with ART and DHA resulted in decreased mouse double minute 2 (MDM2) and increased p53. Generally, p53 is one of the mediators of the mitochondrial apoptotic pathway [66-68]. Interestingly, in p53-null Hep3B cells, we observed the same apoptotic phenomenon, indicating that the ART- and DHA-induced mitochondrial apoptotic pathway can be both p53 dependent and 
independent [51]. The signal transducers and activators of transcription (STAT)3-signaling pathway are upstream of apoptosis inhibitor genes; thus, inhibition of STAT3signaling pathway and increased levels of factor related apoptosis (Fas) on the surface of HepG2 cells promotes apoptosis. Therefore, ART treatment induces apoptosis of HepG2 cells [69]. Another research team also revealed that ART could modulate STAT3-dependent anti-apoptotic and pro-apoptotic expression. Treatment with ART evidently promoted apoptosis of HCC cells, activation of procaspase-3, suppression of $\mathrm{Bcl}-\mathrm{xL}$, and survivin [70]. DHA similarly induced apoptosis in HepG2, PLC/ PRF/5, and Hep3B cells. Zhang and colleagues observed that caspase 9 and 3, but not caspase 8 , largely induced apoptosis in cells exposed to DHA. Additionally, mitochondrial membrane depolarization, PARP cleavage, and cytochrome c release all implied that DHA may induce apoptosis in HCC cells via the intrinsic mitochondrial pathway. However, increased apoptosis was observed in wild-type p53-expressing cells compared to two other cell types, which suggested that p53 may play a role in promoting apoptosis [50]. DHA was found to induce ROS-mediated apoptosis in HepG2 cells in a dose- and time-dependent manner, together with increased intracellular $\left[\mathrm{Ca}^{2+}\right]$ concentrations. Treatment of HepG2 cells with DHA increased Bax protein, growth-arrestand-DNA-damage-inducible gene 153 (GADD153), and apoptotic pathway-related protein levels, but decreased Bcl-2 protein levels [58]. A hybrid of ursodeoxycholic acid and DHA also induced ROS-mediated apoptosis in HepG2 cells, resulting in the upregulation of caspase- 3 and cleaved PARP. This hybrid also induced apoptosis at a much lower concentration in HCC cells than DHA alone [71]. Moreover, DHA induced caspase-dependent apoptosis in SK-Hep-1 cells by inhibiting the Sp1 pathway and activating caspase 8, 9, and 3 [72]. DHA also induced apoptosis in HepG2 and Huh-7 cells via a ROSdependent and Bcl-2 interaction mediator of cell death (Bim)-mediated intrinsic pathway with downregulated myeloid cell leukemia-1 (Mcl-1), while releasing bcl-2 homologous antagonist/killer (Bak) but not Bax [73]. Similarly, Pang and colleagues observed Bax activation, mitochondrial outer membrane permeabilization, cytochrome c release, and caspase 9 and 3 activation. ART also induced apoptosis in a ROS- and Bax-mediated pathway in Hep3B and Huh-7 cells [74]. However, contrary observations were recorded by Qin and colleagues, who reported that ROS induced by ART could not mediate apoptosis in HepG2 cells. Furthermore, ART induced apoptosis via the Bax-mediated intrinsic pathway in which Bcl-2/-xl was involved, but Bim, p53 upregulated modulator of apoptosis (Puma), and Mcl-1 were not involved [75]. In a recent study, ART treatment not only induced the expression of the intrinsic apoptotic markers Bax and Bcl-2, but also increased the levels of caspase-3/7 and cleaved PARP1 in HCC cells $(\mathrm{HuH}-7$ cells and PLC/PRF/5 cells). A combination of sorafenib, a targeted drug for the treatment of liver cancer, with ART exhibited a more significant pro-apoptotic effect [76]. Further studies showed that QBC939, HUCCT-1, and FRH0201 cells exhibited increased apoptotic activity following DHA treatment, which was accompanied by the increased expression of Mcl-1S protein and the increased ratio of Mcl-1S/Mcl-1L [57, 77]. Taken together, artemisinin and its derivatives can induce apoptosis in various cells and through very different pathways within the same cell lines.

\section{Inhibition of angiogenesis, invasion, and metastasis}

Tumor angiogenesis, invasion, and metastasis are principal methods through which cancer cells spread, resulting in high malignance and high mortality of HCC. Epithelial-to-mesenchymal transition (EMT) is a process whereby epithelial cells lose cell-cell adhesion and cell polarity and gain migratory, invasive, and anti-apoptotic abilities to obtain a mesenchymal phenotype [78]. Therefore, it has been regarded as the initiation of metastasis during cancer progression in many recent studies [79, 80]. In SK-HEP1, SM7721, HepG2, and Huh7 HCC cell lines, ART significantly suppressed the occurrence of EMT by decreasing N/E-cadherin, matrix metalloproteinase (MMP)9, and vimentin. According to the analysis of clinical samples in vitro, ART could inhibit EMT, migration, and metastasis by decreasing the expression of LncRNA RP11. Besides, ART directly inhibited invasion and migration of SK-Hep1 and SM7721 cells [81]. Using wound healing and transwell assays, researchers observed that DHA significantly reduced the migration of HepG2215 cells [55], while ART inhibited the invasion and migration of HCCLM3 and MHCC97H cells. Furthermore, HCC cells exposed to ART showed downregulation of pro-metastatic and pro-invasive protein $\mathrm{N}$-cadherin, MMP2, MMP9, and Snail, while the expression of anti-metastatic protein E-cadherin was upregulated, suggesting that ART may suppress the migration and invasion of HCC cells by adjusting the N-cadherinsnail-E-cadherin axis [60]. DHA also inhibited the migration and metastasis of HCCLM6 cells by downregulating fibronectin-1 (FN1) and $\beta 1$-integrin (ITGB1) via the phosphoinositide 3-kinase (PI3K)/AKT signal pathway in vivo and in vitro [59]. Other researchers observed that ART could effectively suppress invasion and metastasis of HepG2 and SMMC7721 cells in vitro, coupled with downregulation of MMP2, upregulation of tissue inhibitor of metalloproteinases (TIMP)2, and degradation of the extracellular matrix (ECM). ART enhanced 
the adhesion of HCC cells through cell division cycle 42 (Cdc42), thereby reducing metastasis [82]. Another study showed that ART reduced the angiogenic factors vascular endothelial growth factor (VEGF) and placental growth factor (PIGF) in vitro and in vivo, suggesting that ART may play a role in inhibiting angiogenesis [83]. Similarly, combination of ART and sorafenib suppressed migration of Huh7 and HepG2 cells [84]. In total, artemisinin and its derivatives have the potential to inhibit angiogenesis, invasion, and metastasis, mainly in relation to cancer cells. Therefore, whether similar effects are observed in non-cancer liver diseases remains to be explored.

\section{Suppression of HSCs}

HSCs are mesenchymal cells that retain features of resident fibroblasts and pericytes [85]. In the presence of various liver injuries, quiescent HSCs are activated, suggesting the beginning of fibrosis, followed by cirrhosis and HCC [86]. ART was shown to inhibit the activation of primary mouse $\mathrm{HSC}$ cells induced by $\mathrm{CCl}_{4}$, and its effect was associated with ferroptosis and activation of ferritinophagy [87]. Wang and colleagues considered that this effect was associated with a p53-dependent mechanism. Meanwhile, the expression of tumor growth factor- $\beta$ receptor 1 (TGF- $\beta$ R1), PDGF- $\beta$ receptor, and epidermal growth factor receptor (EGFR) 31-33 was inhibited after ARM treatment [88]. Similarly, ARM induced the death of HSCs via the ferroptosis pathway, through the action of STIP1 homology and U-box containing protein 1 (STUB1), an enzyme mediating the ubiquitin process of iron regulatory protein 2 (IRP2). ARM inhibited IRP2 binding, thereby increasing IRP2 accumulation in cells, leading to iron accumulation and ROS production [89]. Another study observed that ART weakened the expression of $\alpha$-smooth muscle actin ( $\alpha$-SMA) and collagen I, which were generally regarded as markers of HSC activation, via inhibition of the FAK/AKT/ $\beta$-catenin pathway [64]. ART ameliorated HSC activation through the ceramide synthesis pathway and promoted peroxisome proliferators-activated receptors- $\gamma$ (PPAR- $\gamma$ ) and caspase- 3 upregulation, as well as hydroxyproline downregulation [90].

In addition, ART influenced HSC activation by reducing the expression of mitochondrial complex I subunit NDUFB8 and complex III subunit UQCRC2. ART attenuated the mitochondrial function in HSCs, and this effect could not be seen in the liver-derived cells [91].

\section{Chemosensitization to chemotherapeutic agents}

Drug resistance and tumor recurrence have long been major challenges for cancer treatment [92]. Nevertheless, several studies held that artemisinin and its derivatives could promote sensitivity to other chemotherapeutic agents. Sorafenib $(2.77 \mu \mathrm{M})$ combined with ART was equivalent to $5.23 \mu \mathrm{M}$ sorafenib alone, and induced $50 \%$ inhibition of SK-7721 tumor cells. Moreover, sorafenib combined with ART treatment stimulated RAF/mitogen-activated protein kinase (MAPK) and PI3K/AKT/ mammalian target of rapamycin (mTOR) signaling pathways, a dual inhibitory effect which promoted apoptosis [93]. Similarly, ART advanced cell apoptosis by activating the caspase cascade when combined with sorafenib, and using sorafenib and ART together reduced VEGFR2 protein expression in HepG2 and Huh7 cells [84]. DHA coupled with gemcitabine activated Bax-dependent apoptosis and decreased HepG2 and Hep3B cell survival [51]. Yang et al. showed that mutant p53 (R248Q) induced doxorubicin $(\mathrm{ADM})$ resistance in Hep3B by increasing ADM efflux, AKT, extracellular signal-regulated protein kinases (ERK)1/2, and p65 phosphorylation and P-glycoprotein (P-gp) expression [94]. However, DHA enhanced the pro-apoptotic effects of ADM in Hep3B cells with mutant p53 (R248Q) synergistically, and it was indicated that DHA suppressed the P-gp expression by monitoring the p53 (R248Q)-ERK1/2-NF-kB pathway [95]. Taken together, these studies demonstrated that artemisinins can enhance therapeutic effectiveness of chemotherapeutic drugs through various mechanisms.

\section{Inducing autophagy}

Autophagy is a process involving damaged cell removal, whereby cells eat themselves. It is a crucial for development, differentiation, and survival [96]. Autophagy is an important mechanism used to maintain the stability of intracellular environments, and can respond to various environmental and cellular stresses by mediating lysosome-dependent cell degradation processes [97]. Autophagy may occur in physiological and pathological conditions, indicating that regulated autophagy may serve as a promising therapeutic strategy [98]. Zhang and colleagues found that DHA induced the emergence of autophagosomes and increased autophagic flux in a dose- and time-dependent manner in activated HSCs, while downregulating p-mTOR activity and upregulating p-Unc-like kinase 1 (ULK1) activity [54, 99]. Similarly, in HepG2215 cells, DHA treatment markedly upregulated light chain 3 (LC3) and downregulated p-AKT, p-mTOR, p-ribosomal protein $\mathrm{S} 6$ kinase (p70S6K), and p-4E binding protein 1 (4EBP1), which suggested that DHA may induce autophagy via suppression of the AKT-mTOR pathway [55]. Additionally, LC3 beta (LC3B) conversion and autophagy substrate protein p62/sequestosome 1 (SQSTM1) are used to monitor autophagy [100]. DHA promoted the transformation from LC3B-I to LC3B-II and increased the expression of LC3B-II. Conversely, it 
induced the decreased p62/SQSTM1 in HepG2215 cells [56]. Some studies found that autophagy exerts opposing effects dependent on the cell type [101], which should be of particular concern in the future when using artemisinins to treat liver diseases. The pharmacological effects of artemisinins in vitro models are summarized in Table 2.

\section{Effects of artemisinin and its derivatives in vivo}

Next, we will explore the effects of artemisinins on hepatitis, AFLD, NAFLD, liver fibrosis, and liver cancer, as well as the underlying mechanisms, including oxidative stress, hepatic inflammation, immunoregulation, and tumorigenesis (Table 3).

\section{Effects of artemisinins on hepatic oxidative stress and inflammation}

The anti-oxidative effect of DHA has been demonstrated in weaned piglets with intrauterine growth retardation (IUGR). Previous studies have shown that IUGR is associated with cellular oxidative damage [102, 103]. DHA $(80 \mathrm{mg} / \mathrm{kg})$ effectively increased glutathione (GSH) concentrations and the activity of T-superoxide dismutase (T-SOD), and decreased the concentrations of malondialdehyde (MDA), $\mathrm{H}_{2} \mathrm{O}_{2}$, protein carbonyl (PC), 8-hydroxy2'-deoxyguanosine (8-OhdG), oxidized glutathione (GSSG), and GSSG:GSH ratio in the liver. Further, DHA attenuated oxidative stress due to IUGR by activating the Nrf2/ARE/HO-1 signaling pathway [104]. Oxidative stress is one of the core molecular mechanisms for hepatic ischemia/reperfusion (I/R) injury. ART $(50 \mathrm{mg} /$ $\mathrm{kg}$, intraperitoneal injection) significantly attenuated hepatic I/R injury by increasing GSH and SOD, which combat oxidative stress, and reducing the level of MDA, a marker of lipid peroxidation, at the beginning of the reperfusion period [105].

Additionally, emerging evidence revealed that artemisinins regulate signaling pathways and the production of inflammatory cytokines and chemokines to reduce hepatic inflammation and injury. Toll-like receptor 4 (TLR4) plays a crucial role in regulating inflammation and is unique for containing lipopolysaccharide (LPS). By triggering myeloid differentiation primary response protein 88 (MyD88), NF- $\mathrm{KB}$ protein is activated, leading to the release of inflammatory factors $[106,107]$. An in vivo study demonstrated that ART downregulated the expression of TLR4, MyD88, and NF-kB at both the mRNA and protein levels, and reduced proinflammatory factors TNF- $\alpha$ and IL- 6 in a hepatic injury model induced using several pathogenic factors [108]. Research has shown that $\operatorname{ART}(27,54$, and $108 \mathrm{mg} / \mathrm{kg}$ ) exhibits anti-inflammatory properties and plays a protective role against concanavalin A (Con A)-induced inflammatory activity and autoimmune injury in mouse livers by decreasing the serum levels of aspartate transaminase (AST) and alanine transaminase (ALT) and reducing production of pro-inflammatory cytokines, such as IL-6, IL-1 $\beta$, TNF$\alpha$, IFN- $\gamma$, and IL-17. This effect was mediated mainly by inhibiting the activation of NF- $\mathrm{kB}$ and MAPK pathways [109]. A later study suggested that oral exposure to lithocholic acid (LCA) caused liver injury, but the antiinflammatory activity of artemisinin extract in liver tissues increased the expression of GSH in a LCA-induced mouse model [110]. Chen and colleagues reported that DHA treatment improved hepatic necrosis and infiltration of inflammatory cells, thus playing a protective role in bile duct ligation (BDL)-induced injury in a rat model. Moreover, DHA reduced the levels of serum ALT, AST, TNF- $\alpha$, and IL-6 [111]. IUGR reportedly induces inflammation [112]. Levels of serum AST and ALT and the AST/ALT ratio were high in IUGR-affected piglets, which indicated liver damage. Additionally, the levels of IFN- $\gamma$, TNF- $\alpha$, IL- $1 \beta$, and IL- 6 were found upregulated in the livers of IUGR-affected piglets. However, DHA supplementation reduced the expression of proinflammatory cytokines and played an important role in protecting hepatic function [113]. Another study showed that Artemisia annua leaf (AA) extract improved hepatic inflammation by reducing the expression of high-mobility group box 1 (HMGB1) and cyclooxygenase-2 (COX-2) in high-fat diet (HFD)-fed mice [114].

Several studies have confirmed the role of autophagy as a defense mechanism against inflammation-related diseases $[115,116]$. Zhang and colleagues found that DHA not only inhibited the production and release of inflammatory cytokines (NF- $\mathrm{kB}$, NLRP3, TNF- $\alpha$, IL- $1 \beta$, IL-6, and IL-8), but also promoted the expression of antiinflammatory factors (IL-4 and IL-10) in a $\mathrm{CCL}_{4}$-induced rat model. Furthermore, DHA ameliorated inflammation by inducing autophagy in activated HSCs. Importantly, DHA induced autophagy in HSCs by promoting ROS generation and c-Jun N-terminal kinase (JNK)1/2 activation [54]. Proposed underlying mechanisms are shown in Fig. 1.

\section{Effects of artemisinins on hepatic lipid metabolism (fatty liver diseases)}

In recent years, evidence has accumulated indicating that metabolic syndromes, such as obesity, insulin resistance, diabetes, and hyperlipidemia, and AFLD caused by excessive alcohol consumption are major causes of chronic liver diseases and even HCC [117]. Artemisinin and its derivatives have shown defensive effects on hepatic lipid metabolism disorders (Fig. 2).

AA extract administration significantly decreased the expression of p-acetyl-CoA carboxylase (ACC), 
Table 2 Pharmacological effects of artemisinin and its derivatives on hepatic diseases in vitro

\begin{tabular}{|c|c|c|c|c|c|}
\hline Hepatic disease & Cell lines & Drug & Dosage & Variations & Refs. \\
\hline \multicolumn{6}{|l|}{ Effects on cell cycle } \\
\hline \multirow[t]{2}{*}{$\mathrm{HCC}$} & HepG2 cells, PLC/PRF/5 cells, Hep3B cells & DHA & $20-40 \mu \mathrm{M}$ & $\downarrow$ cyclin B, CDC25C; $\uparrow P 21$, G2/M phase & {$[50]$} \\
\hline & HepG2 cells, Hep3B cells & ART, DHA & $0-50 \mu \mathrm{M}$ & $\begin{array}{l}\downarrow E 2 F 1, \text { CDK2 } \\
\text { CDK3, cyclin D1, cyclin E; } \\
\uparrow G 1 \text { phase, Kip1/p27, Cip/p21 }\end{array}$ & {$[51]$} \\
\hline Liver fibrosis & $\mathrm{HSCs}$ & $\mathrm{DHA}$ & $15-50 \mu \mathrm{M}$ & $\begin{array}{l}\downarrow \text { cyclin A, CDK2; } \\
\uparrow S \text { phase, p53, p21 }\end{array}$ & {$[52]$} \\
\hline \multicolumn{6}{|c|}{ Effects on cell proliferation } \\
\hline \multirow[t]{5}{*}{$\mathrm{HCC}$} & HepG2215 cells & DHA & $50-200 \mu \mathrm{M}$ & $\downarrow c e l l$ proliferation & {$[55]$} \\
\hline & HepG2215 cells & DHA & $5-20 \mu \mathrm{M}$ & $\downarrow c e l l$ proliferation, colony formation & {$[56]$} \\
\hline & HepG2 cells & DHA & $0-200 \mu \mathrm{M} \mathrm{ol} / \mathrm{L}$ & $\begin{array}{l}\downarrow \text { cell proliferation; } \\
\uparrow R O S,\left[\mathrm{Ca}^{2+}\right]\end{array}$ & {$[58]$} \\
\hline & HCCLM6 cells & DHA & $1-100 \mu \mathrm{M}$ & $\begin{array}{l}\downarrow \text { cell proliferation, E2F1, BCL, PCNA, MKI67, } \\
\text { CCNE2 }\end{array}$ & [59] \\
\hline & HCCLM3 cells, MHCC97H cells & ART & $0-100 \mu \mathrm{M}$ & $\begin{array}{l}\downarrow \text { cell growth, colony formation; cell cycle } \\
\text { arrest }\end{array}$ & {$[60]$} \\
\hline CCA & HUCCT-1 cells, FRH201 cells & DHA & $20 \mu \mathrm{M} \mathrm{ol} / \mathrm{L}$ & $\downarrow c e l l$ proliferation & {$[57]$} \\
\hline \multirow[t]{2}{*}{ Liver fibrosis } & $\mathrm{HSCs}$ & ART & $125-225 \mu \mathrm{M} \mathrm{ol} / \mathrm{L}$ & $\downarrow c e l l$ proliferation & [63] \\
\hline & LX-2 cells & ART & $0-50 \mathrm{ug} / \mathrm{ml}$ & $\downarrow c e l l$ proliferation & {$[64]$} \\
\hline \multicolumn{6}{|c|}{ Effects on cell apoptosis } \\
\hline \multirow[t]{2}{*}{ Liver fibrosis } & LX-2 cells & ART & $12.5-50 \mathrm{ug} / \mathrm{ml}$ & $\begin{array}{l}\downarrow \mathrm{BCl}-2 ; \\
\uparrow \mathrm{Bax} / \mathrm{BCl}-2\end{array}$ & {$[64]$} \\
\hline & $\mathrm{HSCS}$ & ART & 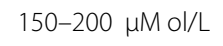 & $\uparrow p 53$ & {$[63]$} \\
\hline \multirow[t]{10}{*}{$\mathrm{HCC}$} & SMMC-7721 cells & Artemisinin & 100-200 $\mu \mathrm{M} \mathrm{ol} / \mathrm{L}$ & 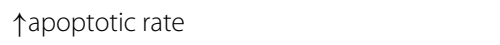 & {$[65]$} \\
\hline & HepG2 cells & ART and DHA & $0-50 \mu \mathrm{M}$ & $\begin{array}{l}\downarrow \text { BCl-2, PARP; } \\
\uparrow \text { Bax, caspase-3, p53, MDM2 }\end{array}$ & {$[51]$} \\
\hline & HepG2 cells & ART & $0.5-8 \mathrm{mg} / \mathrm{L}$ & $\downarrow p-S T A T 3 ; \uparrow F a s$ & [69] \\
\hline & HepG2, cells & DHA & $0-200 \mu \mathrm{M} \mathrm{ol} / \mathrm{L}$ & $\begin{array}{l}\downarrow \mathrm{BCl}-2 ; \\
\uparrow \mathrm{GADD} 153, \mathrm{Bax}\end{array}$ & {$[58]$} \\
\hline & HepG2 cells & DHA & $0-100 \mu \mathrm{M}$ & $\uparrow$ cleaved PARP, caspase-3 & {$[71]$} \\
\hline & SK-Hep-1 cells & DHA & $20-60 \mu \mathrm{M}$ & $\begin{array}{l}\downarrow \text { PARP, Sp1; } \\
\uparrow \text { caspase8, caspase9, caspase3 }\end{array}$ & {$[72]$} \\
\hline & HepG2 and Huh-7 cells & DHA & $0-150 \mu \mathrm{M}$ & $\begin{array}{l}\downarrow \Delta \Psi_{\mathrm{m}}, \mathrm{Mcl}-1 ; \\
\uparrow \text { Bim, cytochrome c, caspase8, } \\
\text { caspase9,caspase3, ROS, Bak }\end{array}$ & [73] \\
\hline & Hep3B and Huh-7 cells & ART & $10-150 \mu \mathrm{M}$ & $\begin{array}{l}\uparrow R O S, \text { Bax, MOMP, cytochrome c, caspase } 9 \text {, } \\
\text { caspase } 3\end{array}$ & {$[74]$} \\
\hline & HepG2 cells & ART & $10-150 \mu \mathrm{M}$ & $\begin{array}{l}\downarrow \Delta \Psi \mathrm{m}, \mathrm{Bcl}-2 / \mathrm{Bcl}-\mathrm{xl} ; \uparrow \text { } \uparrow \text { Bax, caspase8, ROS, } \\
\text { caspase9, caspase3 }\end{array}$ & {$[75]$} \\
\hline & $\mathrm{HuH}-7$ cells and PLC/PRF/5 cells & ART & $1-300 \mu \mathrm{M}$ & $\begin{array}{l}\downarrow \mathrm{BCl}-2 ; \\
\uparrow \mathrm{Bax}, \text { caspase-3/7, cleaved PARP1 }\end{array}$ & [76] \\
\hline CCA & QBC939 cells, HUCCT-1 and FRH201 cells & DHA & $20 \mu \mathrm{M} \mathrm{ol} / \mathrm{L}$ & $\uparrow M c l-1 S, M c l-1 S / M c l-1 L$, apoptotic rate & {$[57,77]$} \\
\hline \multicolumn{6}{|c|}{ Effects on angiogenesis, invasion, metastasis } \\
\hline \multirow[t]{7}{*}{$\mathrm{HCC}$} & SK-HEP1, SM7721, HepG2, and Huh7 cells & ART & $100 \mu \mathrm{M}$ & $\downarrow N / E$-cadherin, MMP9, vimentin, EMT & [81] \\
\hline & HepG2215 cells & $\mathrm{DHA}$ & $100 \mu \mathrm{M}$ & $\downarrow$ Migration ability; & {$[55]$} \\
\hline & HCCLM3 and MHCC97H cells & ART & $25-100 \mu \mathrm{M}$ & $\begin{array}{l}\downarrow N \text {-cadherin, MMP2, MMP9, Snail, } \\
\text { E-cadherin }\end{array}$ & {$[60]$} \\
\hline & HCCLM6 cells & DHA & $50-100 \mu \mathrm{M}$ & $\downarrow F N 1$, ITGB1 & [59] \\
\hline & HepG2 and SMMC-7721 cells & ART & $12.5-75 \mu \mathrm{M}$ & $\begin{array}{l}\downarrow M M P 2 ; \\
\uparrow T I M P 2\end{array}$ & [82] \\
\hline & HepG2 cells & ART & $6.25-50 \mathrm{mmol} / \mathrm{L}$ & $\downarrow V E G F, P I G F$ & {$[83]$} \\
\hline & HepG2 and Huh7 cells & ART & $25 \mu \mathrm{M}, 125 \mu \mathrm{M}$ & $\downarrow$ Cell migration & {$[84]$} \\
\hline
\end{tabular}


Table 2 (continued)

\begin{tabular}{|c|c|c|c|c|c|}
\hline Hepatic disease & Cell lines & Drug & Dosage & Variations & Refs. \\
\hline \multicolumn{6}{|c|}{ Effects on hepatic stellate cells } \\
\hline \multirow[t]{6}{*}{ Liver fibrosis } & Mouse HSCs and LX-2 cells & ART & $25-75 \mu \mathrm{M}$ & $\begin{array}{l}\downarrow \text { Cell vaibility, GSH, GPX4, NADPH, a-SMA, } \\
\text { collagen 1, fibronectin, desmin, FTH1, } \\
\text { NCOA4, p62; } \\
\uparrow \text { cell death, Fe } \\
\text { ROS, ferroptosis, } \\
\text { LC3; mitochondria morphology change }\end{array}$ & {$[87]$} \\
\hline & HSC-T6 cells & ARM & $10-40 \mathrm{ug} / \mathrm{ml}$ & $\begin{array}{l}\downarrow \text { a-SMA, collagen 1, fibronectin, TGF- } \beta \text {, } \\
\text { PDGF- } \beta, \text { EGF, cell viability, GSH, NADPH, } \\
\text { Gpx4, SLC7A11; } \\
\uparrow \text { cell death, Fe } 2+\text {, ROS1, ferroptosis, p53; } \\
\text { mitochondria morphology change }\end{array}$ & {$[88]$} \\
\hline & LX-2 cells & ARM & $10-40 \mathrm{ug} / \mathrm{ml}$ & $\begin{array}{l}\downarrow \text { cell activation; } \\
\uparrow \text { cell death, } \mathrm{Fe}^{2+}, \mathrm{ROS}, \mathrm{MDA}, \mathrm{LPO} \text {, ferropto- } \\
\text { sis, IRP2 }\end{array}$ & {$[89]$} \\
\hline & LX-2 cells & ART & $12.5-50 \mathrm{ug} / \mathrm{ml}$ & $\begin{array}{l}\downarrow \text { cell activation, a-SMA, collagen 1, p-Akt, } \\
\text { p-FAK, p-GSK-3ß }\end{array}$ & [64] \\
\hline & LX-2 cells & ART & 350umol/L & $\begin{array}{l}\downarrow \text { hydroxyproline; } \\
\uparrow \text { ceramide synthase protein, ceramide, } \\
\text { PPAR- } \gamma \text {, caspase-3 }\end{array}$ & {$[90]$} \\
\hline & LX-2 cells & ART & $50-200 \mu \mathrm{M}$ & $\begin{array}{l}\downarrow \text { cell viability, Col1a1, Col3a1, OGDH, CS, } \\
\text { IDH2, mitochondrial function, NDUFB8, } \\
\text { UQCRC2; } \\
\uparrow \text { Cell apoptosis }\end{array}$ & [91] \\
\hline \multicolumn{6}{|c|}{ Effects on cell autophagy } \\
\hline \multirow[t]{2}{*}{ Liver fibrosis } & Primary rat HSCs & DHA & $5-20 \mu \mathrm{M}$ & $\begin{array}{l}\downarrow \text { P62, inflammatory factors, GSH/GSSG; } \\
\uparrow \text { autophagosome, autophagic flux, LC3-II, } \\
\text { ROS, p-JNK1/2 }\end{array}$ & {$[54]$} \\
\hline & Primary rat HSCs & DHA & 5-20 $\mu \mathrm{M}$ & $\begin{array}{l}\text { } \text { autophagosome, p-ULK1, p-mTOR, Atg6/ } \\
\text { Beclin1, LC3-II, p53, GATA6, cell senescence }\end{array}$ & [99] \\
\hline \multirow[t]{2}{*}{$\mathrm{HCC}$} & HepG2215 cells & DHA & $100 \mu \mathrm{M}$ & $\begin{array}{l}\downarrow p-A K T, p-m T O R, p-p 70 S 6 K, p-4 E B P 1 ; \\
\uparrow L C 3, p-A M P K, p 62\end{array}$ & {$[55]$} \\
\hline & HepG2215 cells & $\mathrm{DHA}$ & $21.5 \mu \mathrm{M}$ & $\begin{array}{l}\downarrow \mathrm{p} 62 / \mathrm{SQSTM} 1 \\
\uparrow \mathrm{LC} 3 \mathrm{~B}-\|\end{array}$ & {$[56]$} \\
\hline \multicolumn{6}{|c|}{ Effects on chemsensitization to chemotherapeutic agents } \\
\hline \multirow[t]{4}{*}{$\mathrm{HCC}$} & SM-7721, SK-hep1 cells & ART & $50 \mu \mathrm{M}$ & $\begin{array}{l}\text { Chemosensitize with Sor, } \downarrow \text { IC50, cell viability, } \\
\text { p-RAF, p-ERK, p-AKT, p-mTOR; } \\
\uparrow \text { cell apoptosis, p-PARP }\end{array}$ & [93] \\
\hline & $\begin{array}{l}\text { HepG2 cells } \\
\text { Huh7 cells }\end{array}$ & ART & $\begin{array}{l}25 \mu \mathrm{M} \\
125 \mu \mathrm{M}\end{array}$ & $\begin{array}{l}\text { Chemosensitize with Sor, } \downarrow \text { IC } 50 \text {, VEGFR2; } \\
\uparrow \text { cell apoptosis, cleaved caspase-9, cleaved } \\
\text { PARP }\end{array}$ & {$[84]$} \\
\hline & HepG2 and Hep3B cells & ART and DHA & $10 \mu \mathrm{mol} / \mathrm{L}$ & $\begin{array}{l}\text { Chemosensitize with gemcitabine, } \downarrow \text { cell } \\
\text { survival }\end{array}$ & [51] \\
\hline & Hep3B cells & DHA & $5 \mu \mathrm{M}$ & $\begin{array}{l}\text { Chemosensitize with ADM, } \downarrow \text { cell viability, } \\
\text { clone, P-gp, p-ERK1/2, p65; } \\
\uparrow \text { cell apoptosis }\end{array}$ & [95] \\
\hline
\end{tabular}

carbohydrate-responsive element-binding protein (ChREBP), and sterol regulatory element-binding protein 1 (SREBP1), the regulators of lipid synthesis, and improved hepatic triglyceride (TG) levels, body weight, and insulin resistance in HFD-fed mice [114]. A study reported that $0.25 \mathrm{mg} / \mathrm{kg}$ artemisinin demonstrated beneficial effects in inflammatory obese mice by decreasing adipose stores and NAFLD/ non-insulin-dependent diabetes mellitus (NIDDM) in hepatic tissue [118]. In
IUGR-affected piglets, the serum total cholesterol (TC), very-low-density lipoprotein cholesterol (VLDL-C), and non-esterified fatty acid (NEFA) concentrations were high, while total lipase (TL), hepatic lipase (HL), and lipoprotein lipase (LPL) activities of the liver were decreased. However, DHA treatment reversed the above phenomena by promoting the adenosine 5'-monophosphate-activated protein kinase (AMPK)/SIRT1 signaling pathway in the liver to ameliorate lipid metabolism [113]. 
Table 3 Pharmacological effects of artemisinin and its derivatives on hepatic diseases in vivo

\begin{tabular}{|c|c|c|c|c|c|}
\hline Hepatic disease & Animals/stimulation (model) & Drug & Dosage/administration route & Variations & Ref \\
\hline \multicolumn{6}{|c|}{ Effects on oxidative stress and inflammation } \\
\hline Liver injury & $\begin{array}{l}\text { Newborn piglets / } \\
\text { IUGR }\end{array}$ & DHA & $80 \mathrm{mg} / \mathrm{kg}$; orally & $\begin{array}{l}\downarrow \text { MDA, H2O2, PC, 8-OhdG, GSSG, } \\
\text { GSSG:GSH; } \\
\text { 个T-SOD, T-AOC, GSH, Nrf2, HO-1 }\end{array}$ & [104] \\
\hline Liver injury & Adult male Wistar rats///R insult & ART & 50 mg/kg; i.p & $\begin{array}{l}\downarrow \text { NLRP3, NF-KB, TNF-a, IL-18, } \\
\quad \mid \mathrm{L}-1 \beta, \mathrm{HMGB} 1, \| \mathrm{LL}-6\end{array}$ & [105] \\
\hline Liver fibrosis & $\begin{array}{l}\text { Sprague-Dawley rats/multiple } \\
\text { pathogenic factors }\end{array}$ & ART & 28.8 mg/kg; orally & $\downarrow T N F-a, I L-6, N F-k B$ p65 & [108] \\
\hline Autoimmune hepatitis & Male Balb/c mice/ConA & ART & $27,54,108 \mathrm{mg} / \mathrm{kg}$; oral gavage & 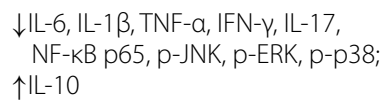 & [109] \\
\hline Cholestatic hepatitis & Adult male mice/lithocholic acid & Artemisinin & 100 mg/kg; oral gavage & $\uparrow G S H, M R P 2, C R A, F X R$ & [110] \\
\hline Liver fibrosis & Male Sprague-Dawley rats/BDL & $\mathrm{DHA}$ & $\begin{array}{l}\text { 3.5, 7, } 14 \mathrm{mg} \\
\text { /kg; i.p }\end{array}$ & $\begin{array}{l}\downarrow \text { liver/body weight, serum AST, } \\
\text { ALT, TNF-a, IL-6 }\end{array}$ & [111] \\
\hline Liver injury & Newborn piglets/IUGR & DHA & 80 mg/kg/d; orally & $\begin{array}{l}\downarrow \text { AST/ALT ratio, TNF- } a, \text { IL- } 6, \| L-1 \beta, \\
\text { IFN- } \gamma\end{array}$ & [113] \\
\hline NAFLD & $\begin{array}{l}\text { Male C57BL/6 J mice/High-fat } \\
\text { diet }\end{array}$ & AA extract & 400 mg/kg/day; orally & $\downarrow C O X-2$, TGF- $\beta 1$, HMGB1 & [114] \\
\hline Liver fibrosis & Male Sprague-Dawley rats/CCl4 & DHA & $\begin{array}{l}\text { 3.5, } 7,14 \mathrm{mg} \\
\text { /kg; i.p }\end{array}$ & $\begin{array}{l}\downarrow N F-k B, T N F-a, I L-6, \text { IL-8, NLRP3, } \\
\quad|\mathrm{L}-1 \beta ; \uparrow| \mathrm{IL}-4, \mathrm{IL}-10, \mathrm{ROS}, \mathrm{JNK} 1 / 2\end{array}$ & [54] \\
\hline AFLD & $\begin{array}{l}\text { Male Sprague-Dawley rats/ } \\
\text { alcohol }\end{array}$ & DHA & 7 mg/kg/day; i.p & $\downarrow T N F-a, N F-k B, N L R P 3$ & [120] \\
\hline \multicolumn{6}{|c|}{ Effects on lipid metabolism } \\
\hline NAFLD & Male C57BL/6J mice/High-fat diet & AA extract & 400 mg/kg/day; orally & $\begin{array}{l}\downarrow \text { body weight, liver weight, TG, } \\
\text { ChREBP, SREBP1; } \\
\uparrow p-A C C\end{array}$ & [114] \\
\hline NAFLD & Female SWISS mice/HFD + LPS & Artemisinin & 0.25 mg/kg/day; i.p & $\begin{array}{l}\downarrow N O S 2 ; \\
\uparrow \text { adipolysis }\end{array}$ & [118] \\
\hline Liver injury & Newborn piglets/IUGR & DHA & 80 mg/kg/d; orally & $\begin{array}{l}\downarrow \text { TC, VLDL-C, NEFA, FAS, ACC }, \\
\text { SREBP-1; } \\
\text { 个HDL-C, LPL, HL, TL, AMPKa, } \\
\text { SIRT1, CPT-1 }\end{array}$ & [113] \\
\hline AFLD & $\begin{array}{l}\text { Male Sprague-Dawley rats/ } \\
\text { alcohol }\end{array}$ & DHA & 7 mg/kg/day; i.p & $\begin{array}{l}\downarrow T C, \text { TG, FAS, SREBP- } 1 c ; \\
\uparrow P P A R-a, \text { CPT1, FXR }\end{array}$ & [120] \\
\hline AFLD & Male ICR mice/alcohol & $\mathrm{DHA}$ & 20 mg/kg/day; i.p & $\begin{array}{l}\downarrow \text { SREBP-1c, SCD1; } \\
\text { } P \text { PPAR-a, FGF21, FSP27,VNN1 }\end{array}$ & [122] \\
\hline AFLD & Male ICR mice/alcohol & $\mathrm{DHA}$ & 7 mg/kg/day; i.p & $\begin{array}{l}\downarrow \operatorname{lipin}-1 \beta \text {, FAS, SREBP-1 C, SCD; } \\
\uparrow \text { PPAR-a, CPT1a }\end{array}$ & [123] \\
\hline \multicolumn{6}{|c|}{ Effects on cell apoptosis } \\
\hline Liver fibrosis & Male Sprague-Dawley rats/BDL & $\mathrm{DHA}$ & $\begin{array}{l}3.5,7,14 \mathrm{mg} \\
/ \mathrm{kg} ; \mathrm{i.p}\end{array}$ & $\begin{array}{l}\downarrow \text { Bcl-2, p-ATK, p-PI3K; } \uparrow \text { HSCs } \\
\text { apoptosis, Bax, cleaved } \\
\text { caspase-9, cleaved caspase-3, } \\
\text { cleaved PARP-1, Cyt c }\end{array}$ & [111] \\
\hline AFLD & Male ICR mice/alcohol & DHA & 20 mg/kg/day; i.p & $\begin{array}{l}\downarrow \text { hepatocytes apoptosis, cas- } \\
\text { pase-9/-3, PUMA, Bim }\end{array}$ & [122] \\
\hline AFLD & Male ICR mice/alcohol & DHA & 7 mg/kg/day; i.p & $\begin{array}{l}\downarrow \text { hepatocyte lipoapoptosis, } \\
\text { caspase-9/3; } \\
\uparrow \mathrm{BCl}-2\end{array}$ & [123] \\
\hline Liver injury & Adult male Wistar rats///R insult & ART & 50 mg/kg; i.p & $\begin{array}{l}\downarrow \text { hepatocytes apoptosis, Bax; } \\
\uparrow B c-2\end{array}$ & [105] \\
\hline Liver cancer & $\begin{array}{l}\text { Mice/Subcutaneous injection of } \\
\text { Hep G2 cells }\end{array}$ & DHA & 20 mg/kg; i.p & $\begin{array}{l}\downarrow \text { weights of Hep G2 xenografts, } \\
\text { Mcl- } 1 \text {, } \\
\uparrow \text { Bak, cleaved caspase } 3\end{array}$ & {$[50]$} \\
\hline Liver cancer & $\begin{array}{l}\text { Mice/Subcutaneous injection of } \\
\text { Hep G2 cells }\end{array}$ & DHA & 5 mg/kg; i.p & $\begin{array}{l}\downarrow M c l-1, p-\text {-ERK, } \\
\uparrow P A R P, \text { necrosis }\end{array}$ & [129] \\
\hline
\end{tabular}


Table 3 (continued)

\begin{tabular}{|c|c|c|c|c|c|}
\hline Hepatic disease & Animals/stimulation (model) & Drug & Dosage/administration route & Variations & Ref \\
\hline \multicolumn{6}{|c|}{ Effects on hepatic fibrogenesis } \\
\hline Liver fibrosis & $\begin{array}{l}\text { Sprague-Dawley rats/multiple } \\
\text { pathogenic factors }\end{array}$ & ART & 28.8 mg/kg; orally & $\begin{array}{l}\downarrow \text { TLR4, MyD } 88, \text { TGF- } \beta 1 \text {, collagen, } \\
\text { a-SMA }\end{array}$ & [108] \\
\hline Liver fibrosis & $\begin{array}{l}\text { Male Sprague-Dawley rats/bile } \\
\text { duct ligation }\end{array}$ & DHA & $3.5,7,14$ mg/kg; i.p & $\begin{array}{l}\downarrow \text { HSC activation, PDGF, PDGF- } \beta \text { R, } \\
\text { TGF- } \beta R I, \text { TGF- } \beta R I I, \text { EGFR, } \\
\text { p-ERK, a-SMA, a1 (I) collagen, } \\
\text { fibronectin, TIMP-1; } \\
\uparrow P P A R Y\end{array}$ & {$[52]$} \\
\hline Liver fibrosis & Male Sprague-Dawley rats/BDL & $\mathrm{DHA}$ & $\begin{array}{l}3.5,7,14 \mathrm{mg} \\
/ \mathrm{kg} ; \mathrm{i.p}\end{array}$ & $\begin{array}{l}\downarrow \text { Collagen, a-SMA, a1 (I) procol- } \\
\text { lagen and fibronectin, TGF- } \beta \text { RII, } \\
\text { PDGF- } \beta R, \text { EGFR }\end{array}$ & [111] \\
\hline Liver fibrosis & Male ICR mice/CCI4 & ART & $50,100,200$ mg/kg/day; i.p & $\begin{array}{l}\downarrow a-S M A, \text { collagen } 1, \text { fibronectin, } \\
\text { desmin }\end{array}$ & {$[87]$} \\
\hline Liver fibrosis & Male ICR mice/CCI4 & ARM & 5, 10, 20 mg/kg; i.p & $\begin{array}{l}\downarrow \text { hydroxyproline, a-SMA), a1 (I) } \\
\text { collagen, fibronectin, PDGF- } \beta \text { R, } \\
\text { EGFR }\end{array}$ & [88] \\
\hline Liver fibrosis & $\begin{array}{l}\text { Male wistar rats/bovine serum } \\
\text { albumin }\end{array}$ & ART & $\begin{array}{l}\text { 3.2, 9.6, 28.8, } 53.1 \mathrm{mg} / \mathrm{kg} \text {; oral } \\
\text { gavage }\end{array}$ & $\begin{array}{l}\downarrow \text { collagen, a-SMA, type I col- } \\
\text { lagen, MMP-2, MMP-9; } \\
\uparrow \text { MMP-13 }\end{array}$ & [126] \\
\hline Liver fibrosis & Male ICR mice/CCI4 & DHA & 7 mg/kg/day; i.p & $\begin{array}{l}\downarrow \text { a-SMA, fibrotic, nodular; } \\
\uparrow F X R\end{array}$ & {$[127]$} \\
\hline \multicolumn{6}{|c|}{ Effects on autophagy } \\
\hline Liver fibrosis & Male Sprague-Dawley rats/CCI4 & $\mathrm{DHA}$ & $\begin{array}{l}3.5,7,14 \mathrm{mg} \\
\text { /kg; i.p }\end{array}$ & $\begin{array}{l}\downarrow \text { p62, } \\
\uparrow \text { autophagosome, LC3-II, ROS, }\end{array}$ & [54] \\
\hline Liver fibrosis & Male Sprague-Dawley rats/CCI4 & DHA & $\begin{array}{l}3.5,7,14 \mathrm{mg} \\
\text { /kg; i.p }\end{array}$ & $\begin{array}{l}\downarrow p-m T O R ; \\
\text { } \text { HSC senescence, p53, p16, } \\
\text { GATA6, autophagosome, LC3-II, } \\
\text { p-ULK1 }\end{array}$ & [99] \\
\hline \multicolumn{6}{|c|}{ Effects onferroptosis } \\
\hline Liver fibrosis & Male ICR mice/CCI4 & ART & $50,100,200$ mg/kg/day; i.p & $\begin{array}{l}\downarrow G S H ; \\
\uparrow F e 2+, \text { lipid ROS, Ptgs2 }\end{array}$ & {$[87]$} \\
\hline Liver fibrosis & Male ICR mice/CCI4 & ARM & 5, 10, 20 mg/kg; i.p & $\begin{array}{l}\text { Small and ruptured mitochon- } \\
\text { dria; } \downarrow \text { Gpx4, SLC7A11; } \\
\text { 个ROS1, P53 }\end{array}$ & [88] \\
\hline \multicolumn{6}{|c|}{ Effects on metastasis } \\
\hline Liver disease & $\begin{array}{l}\text { Male athymic BALB/c nu/nu } \\
\text { mice/orthotopic xenografts }\end{array}$ & Artemisinin & $0,50,100 \mathrm{mg} / \mathrm{kg}$; oral gavage & $\downarrow$ lung tumors & {$[82]$} \\
\hline
\end{tabular}

i.p. Intraperitoneal injection

Interestingly, ARM was found to reduce liver fat vacuoles, improve hepatic insulin resistance, and decrease fat deposition in $\mathrm{db} / \mathrm{db}$ mice [119]. Chronic, abundant alcohol consumption is a significant cause of lipid metabolism disorders. $\mathrm{Xu}$ and colleagues confirmed that DHA eliminated the alcohol-induced expression of proinflammatory factors, such as TNF- $\alpha, \mathrm{NF}-\mathrm{kB}$, and NLRP3. DHA administration also reduced intrahepatic CD45-, F4/80-, and CD68-positive cells and monocyte chemotactic protein-1 (MCP-1) expression. On the contrary, DHA treatment decreased serum levels of TG, TC, and low-density lipoprotein cholesterol (LDL-C), which further prevented fat deposition. The specific farnesoid X receptor (FXR) antagonist Z-guggulsterone reduced DHA-induced effects significantly [120]. Activation of the endoplasmic reticulum (ER) stress-mediated mitochondrial pathway also plays an important role in the pathogenesis of AFLD. ER stress induced by alcohol promoted the expression of key lipogenic enzyme SREBP-1c, leading to increased fat synthesis and resulting in lipid metabolism disorders [121]. Furthermore, Chen and colleagues demonstrated that DHA $(5,10,20 \mu \mathrm{M})$ prevents ER stress and mitochondrial apoptotic pathway activation, and inhibits JNK activation and expression of C/EBP homologous protein (CHOP). DHA attenuated alcohol-induced lipid accumulation in mouse livers by suppressing stearoyl-CoA-desaturase 1 (SCD1), Fas, and SREBP-1c, while increasing the expression of PPAR- $\alpha$ and carnitine palmitoyltransferase $1 \mathrm{~A}(\mathrm{CPT}-1 \mathrm{~A})$, the regulator of fatty acid oxidation [122]. Additionally, a previous study reported that DHA 


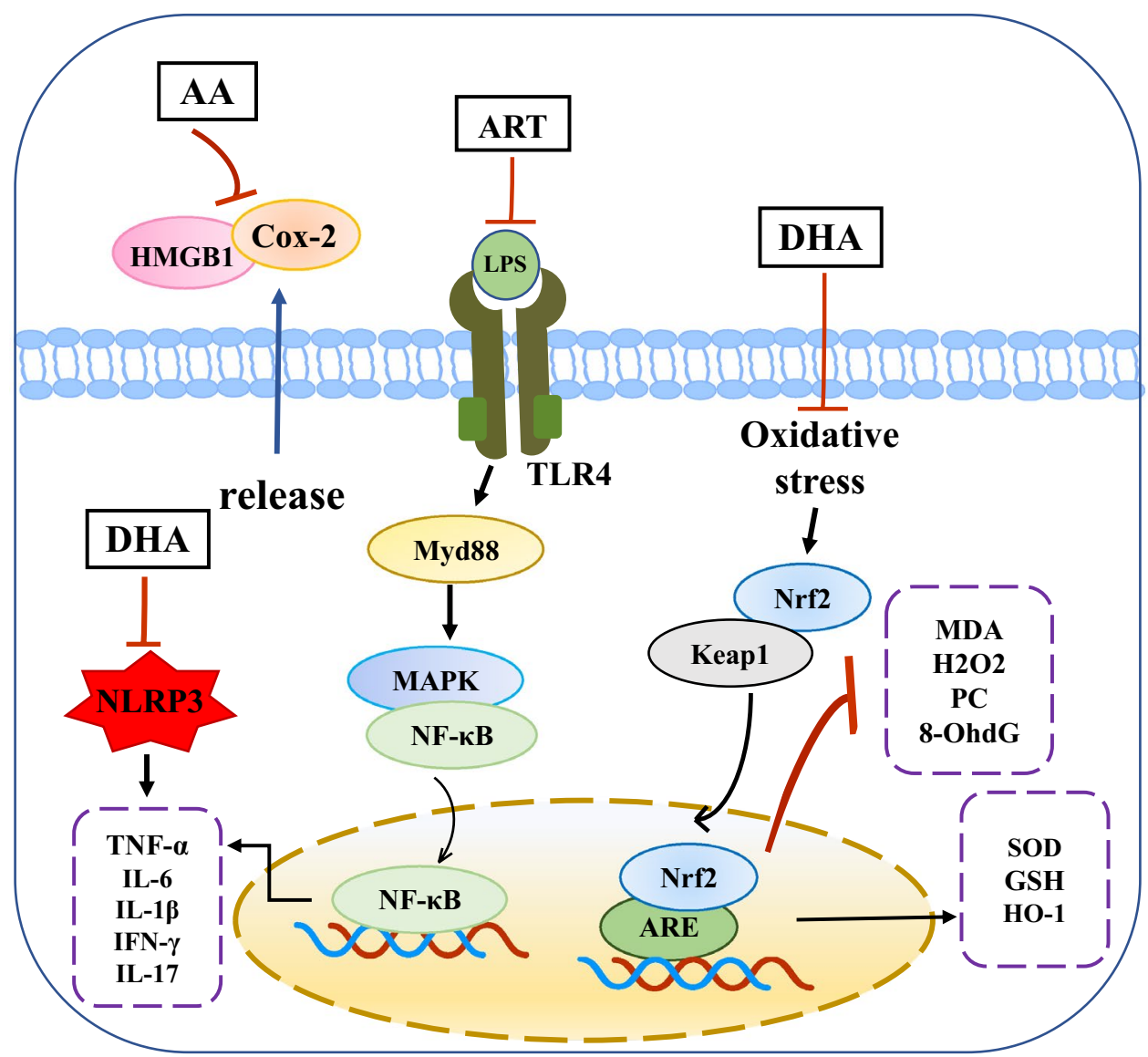

Fig. 1 Effects of artemisinin and its derivatives on hepatic oxidative stress and inflammation

regulated nucleocytoplasmic shuttling of lipin-1 to alleviate alcohol-induced liver impairment in mice [123].

\section{Effects of artemisinins on liver fibrosis}

Liver fibrosis, a decompensated repair process following many chronic injuries, is characterized by the activation of HSCs, accumulation of ECM, and hepatic inflammation. Liver fibrosis often develops into cirrhosis, liver failure, portal hypertension, and HCC, and therefore urgently requires effective treatment $[124,125]$. The effect of artemisinins on liver fibrosis and possible molecular mechanisms of action are summarized below (Fig. 3). ART (28.8 mg/kg) treatment decreased TNF- $\alpha$, IL-6, $\alpha$-SMA, TLR4, MyD88, NF-kB, and TGF- $\beta 1$ levels in rats, demonstrating that it may ameliorate hepatic fibrosis by inhibiting liver inflammation [108]. In addition, previous studies showed that DHA disrupts HSC proliferation and promotes HSC apoptosis to prevent the progress of liver fibrosis in a BDL rat model [52, 111]. A recent study verified that ART induced ferritinophagymediated ferroptosis in $\mathrm{HSCs}$ in a $\mathrm{CCL}_{4}$-induced mouse model. Chloroquine inhibits ART-induced anti-fibrosis functions by eliminating ferritinophagy [87]. More importantly, p53, a tumor suppressor, was observed upstream of HSC ferroptosis, indicating that ARM alleviated hepatic fibrosis by mediating p53-dependent ferroptosis [88]. Another study found that DHA could treat liver fibrosis by inducing HSC autophagy [54]. Furthermore, DHA may promote HSC senescence by inducing the generation of GATA binding protein 6 (GATA6), in which the activation of autophagy plays an important role [99]. Meanwhile, ART prevented bovine serum albumininduced liver fibrosis by decreasing hydroxyproline levels and inhibiting MMP-2, MMP-9, $\alpha$-SMA, and type I collagen expression [126]. Interestingly, artemisinins not only ameliorated fibrosis by inhibiting HSC activation, but also treated portal hypertension via inhibition of HSC contraction. $\mathrm{Xu}$ and colleagues found that DHA inhibited HSC contraction by activating FXR and restraining contractile regulators, such as sphingosine-1-phosphate receptor 2 (S1PR2), phospho-myosin phosphatase target subunit 1 (p-MYPT1), rho-associated kinase (ROCK), myosin light chain kinase (MLCK), and phospho-myosin light chain (p-MLC) in rat HSCs [127]. 


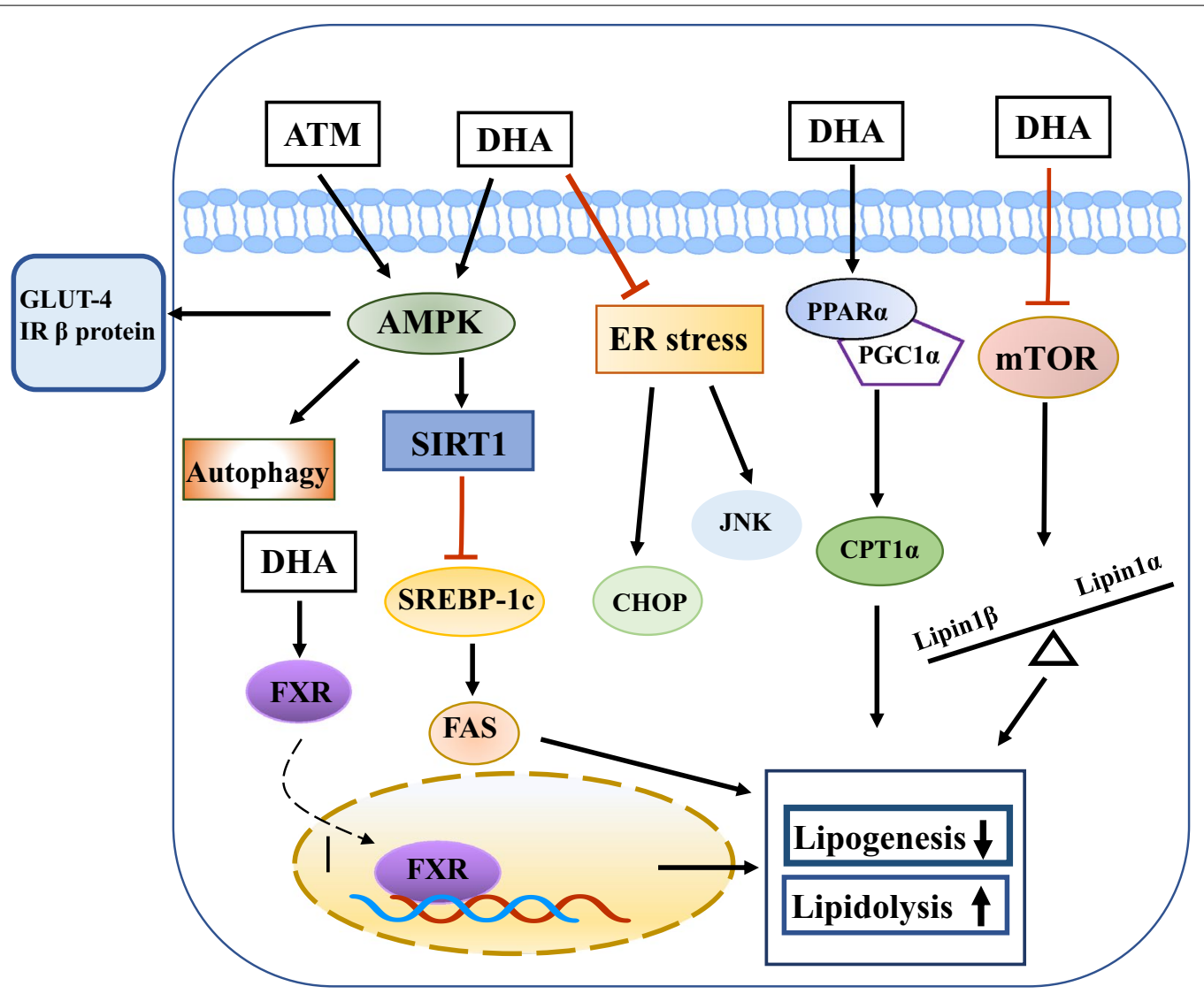

Fig. 2 Effects of artemisinin and its derivatives on hepatic energy metabolism

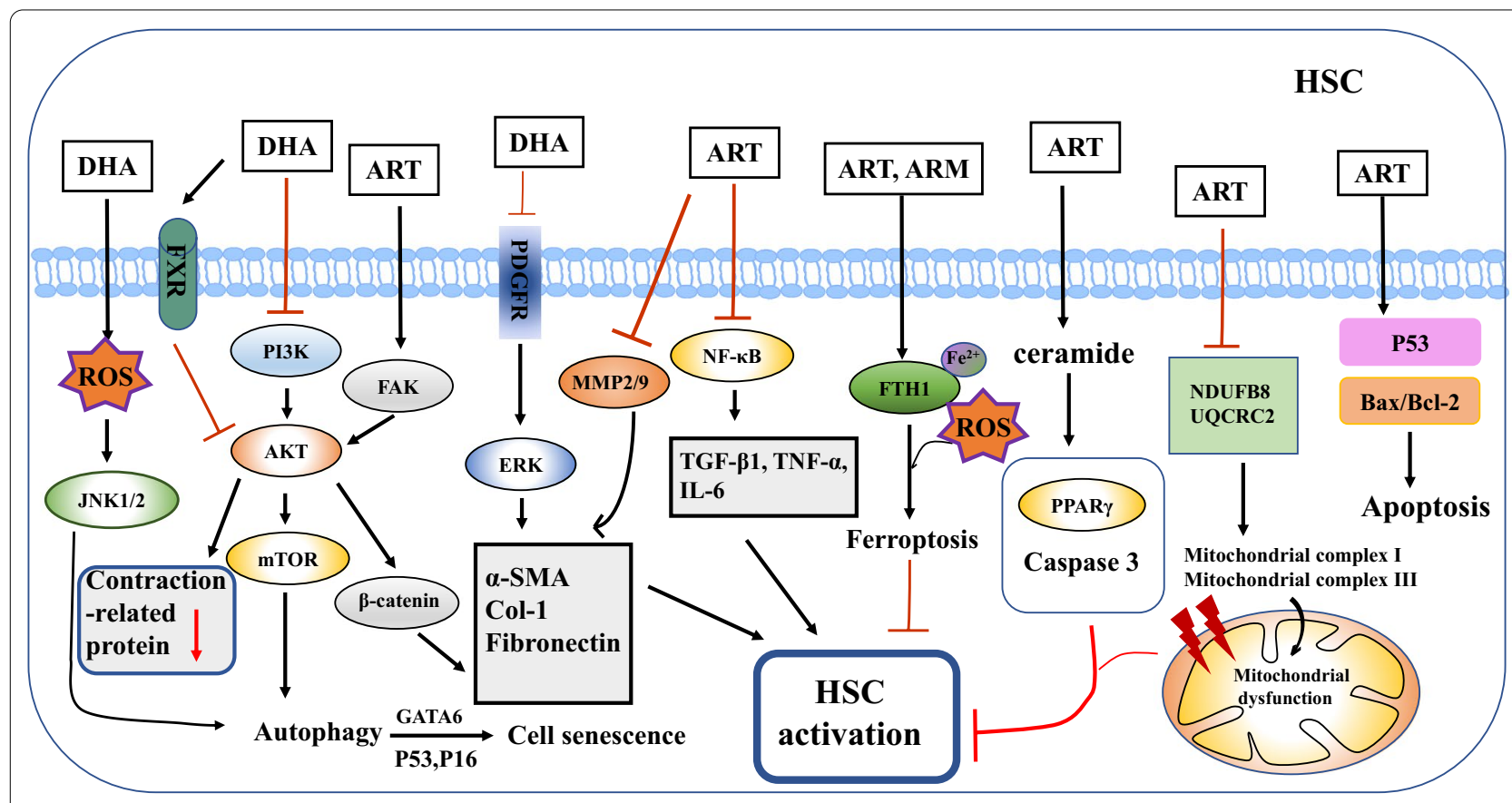

Fig. 3 Effects of artemisinin and its derivatives on liver fibrosis 


\section{Effects of artemisinins on liver cancers}

$\mathrm{HCC}$ is the primary type of liver cancer, with high incidence and mortality rates [128]. However, treating HCC is still a clinical challenge with poor prognosis due to tumor metastasis, chemoresistance, and recurrence after surgery. Increasing evidence has shown that artemisinin and its derivatives have anti-tumor effects (Fig. 4). Zhang and colleagues found that $20 \mathrm{mg} / \mathrm{kg}$ DHA largely reduced the weights of HepG2 xenografts in mouse models, which was accompanied with the upregulation of Bak and caspase 3 and downregulation of Mcl-1 [50]. Additionally, DHA decreased cancer cells and induced apoptosis and inflammatory cell infiltration in tumor sections [129]. Another study reported that, compared with the control group, ART treatment reduced the number of tumors in the lungs of mice after liver inoculation with HepG2 tumor tissue, which indicated that ART possibly inhibited metastasis of HCC in vivo [82]. Recently, research has indicated that the IL-6/JAK/STAT signaling pathway was involved in the development and progression of HCC [130]. ART (25 mg/kg bodyweight) significantly prevented nitrosodiethylamine-induced hepatocarcinogenesis by downregulating the expression of IL-6, GP130, JAK-2, and STAT-3(pY705) in rats [131]. Interestingly, cellular-myelocytomatosis viral oncogene (c-Myc) reportedly protects human tumor cells from DNA damage by inducing the expression of topoisomerases. However, by promoting the expression of the c-Myc E3 ligase neural precursor cell expressed developmentally downregulated gene 4 (NEDD4), artemisitene (ATT) treatment destabilized c-Myc in tumor cells and damaged the DNA of tumor cells, thus playing an anti-tumor role [132].

\section{Metabolism of artemisinins and drug interactions}

The liver is the primary organ of drug metabolism and is rich in various enzymes required for drug metabolism. Among them, the cytochrome P450 (CYP) enzyme family is the most important and plays a notable role in drug metabolism, cell metabolism, and homeostasis [133]. CYP enzymes involved in drug metabolism include, but are not limited to, CYP1A2, CYP2B6, CYP2C9, CYP2C19, CYP2D6, CYP2E1, and CYP3A4. Research has indicated that artemisinin was mainly metabolized into its active metabolite DHA in liver microsomes [134]. For instance, ARE was metabolized into DHA by CYP3A4, CYP2B6, and CYP3A5, and ART was metabolized to DHA by CYP2A6 [134-136]. Interestingly, the oral clearance rate of artemisinin on the last day of multiple administrations was significantly higher than that on the first administration, indicating that artemisinin can induce an auto-induction phenomenon, partly due to the induction of CYP2B6 [137]. Furthermore, a recent study demonstrated that auto-induction elimination caused by artemisinin might be related to intestinal first-pass effect, likely by inducing CYP3A4 and CYP2B6 in the intestine [138]. Therefore, the route of administration should be considered when artemisinin is used. Artemisinins play a significant role in the induction or inhibition of CYP enzymes, which is the main mechanism of drug interaction. We previously found that artemisinin, ARM, and ARE significantly decreased the metabolic elimination of carbamazepine from livers through the inhibition of hepatic CYP3A4 enzyme activity in rabbits [139]. Furthermore, there was also an interaction between artemisinins and other drugs, such as efavirenz, protease inhibitors, and S-mephenytoin [134, 137, 140]. The potential drug-drug interactions were mainly generated

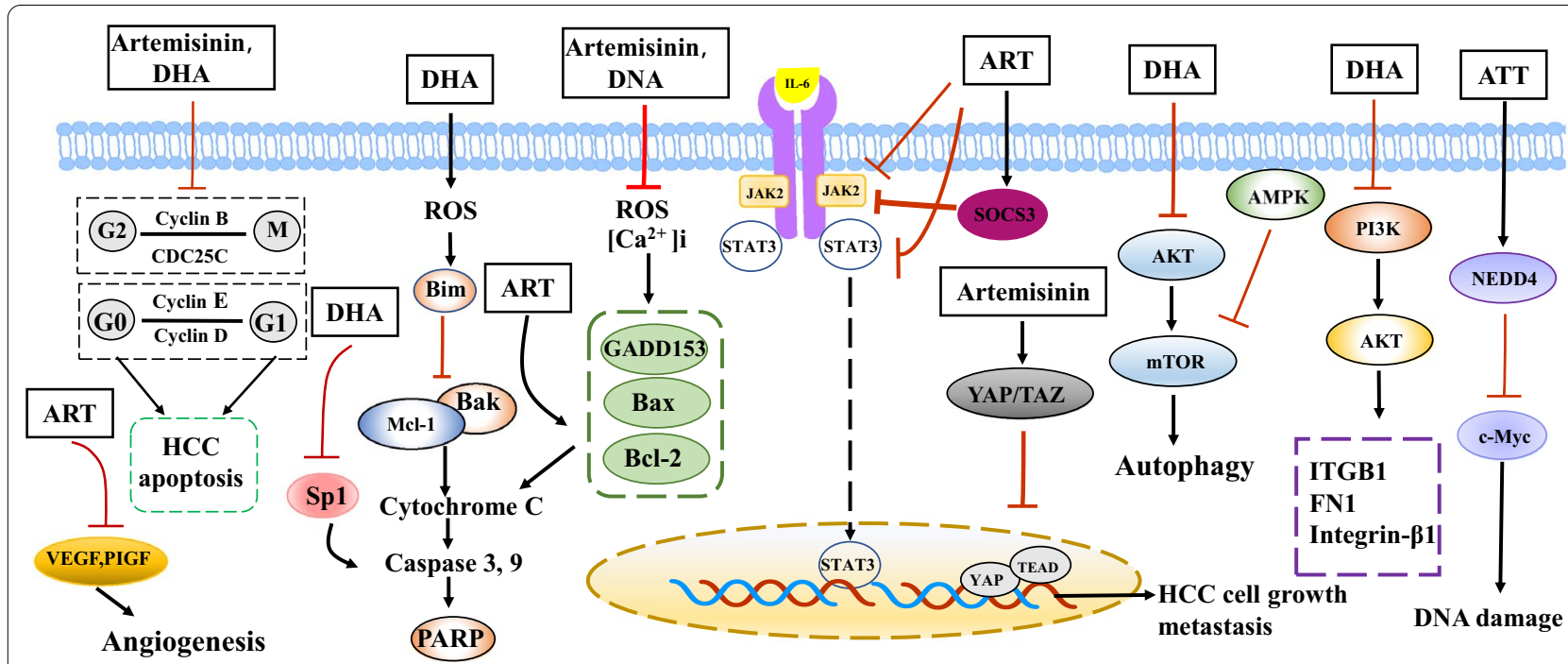

Fig. 4 Molecular targets of artemisinin and its derivatives in liver cancer 
by regulation of CYP3A, CYP2B6, and CYP2C19. Apart from drugs, artemisinin also weakened the metabolism of caffeine in healthy subjects by inhibiting CYP1A2 activation [141]. The above findings suggest that drug-drug interactions must be considered when administering artemisinins.

\section{Toxicology}

Thousands of patients have been treated with artemisinins to combat malaria, and no major adverse effects have been reported yet. Nevertheless, this alone is not strong enough evidence for the drug's safety. A large meta-analysis including thousands of patients with malaria reported neutropenia, prolonged QT interval, and elevated liver enzymes in $1.3 \%, 1.1 \%$, and $0.9 \%$ of all cases, respectively [142]. Deeken et al. identified that the maximum tolerated dose of intravenous ART was $18 \mathrm{mg} /$ $\mathrm{kg}$ in patients with advanced solid tumors. Interestingly, patients receiving the minimum dose of intravenous ART $(8 \mathrm{mg} / \mathrm{kg}$ ) showed distinct infusion reactions during the follow-up treatment cycle [143]. Recently, some case reports also revealed that the use of artemisinins led to unwanted adverse events. A patient ingesting A. annua tea as a chemoprophylaxis against malaria suffered from severe acute cholestatic hepatitis, combined with increased liver enzyme and liver inflammatory activities $[144,145]$. Further, we found that the association of ART with other drugs led to unexpected adverse events. In one of the cases reported, a glioblastoma multiforme (GBM) patient treated with temozolomide, ART, and Chinese herbal medicines (Coptis chinensis, Siegesbeckia orientalis, Artemisia scoparia, and Dictamnus dasycarpus) developed hepatotoxicity [146]. Though single drug use may induce hepatotoxicity, the combination therapy resulted in significantly increased liver enzyme activities. Another case of a GBM patient was reported; the patient received a combination of dichloroacetate and ART after failed temozolomide treatment and suffered from hepatic damage and bone marrow toxicity, and died a few days later [147]. The compassionate use of dichloroacetate/ART cannot be recommended in the clinical treatment of GBM. These extreme examples illustrate that, although artemisinins alone are considered to be well tolerated, their combination with other medications should be carefully administered. Of course, in many animal experiments, artemisinins exhibited neurotoxicity (cerebral parenchyma and nucleus damage), cardiotoxicity (bradycardia and QTc prolongation), hematotoxicity (leukopenia and thrombocytopenia), genotoxicity, embryotoxicity, and nephrotoxicity [148]. Most evidence reporting these adverse events was obtained from case reports, animal experiments, and reports of combination use of artemisinins with other medications, which introduces controversy when determining if artemisinins are toxic or not. However, it is undeniable that attention should be paid to the administration method, frequency, dosage, and combination of medications when using artemisinin and its derivatives in clinical practice.

\section{Conclusion and future perspectives}

Compared with traditional therapies, the extraction of bioactive natural ingredients from Chinese herbal medicines has become increasingly popular, which may be due to the additional benefits in the prevention and treatment of chronic diseases, such as liver diseases. Artemisinin has played a huge role in the treatment of malaria in modern times. In recent years, artemisinins have also been widely used in the treatment of solid tumors [149, 150], respiratory diseases [32], and immune related diseases [151, 152]. However, the literature lacks systematic reports on the significance of artemisinin and its derivatives in the treatment of chronic hepatic disease. In this review, we summarized and provided an overview of the current knowledge of artemisinin and its derivatives as potential therapeutic targets for the treatment of liver diseases in vitro and in vivo. The important activities of artemisinins could be divided into four aspects: antioxidant, anti-inflammatory, pro-apoptotic, and carcinostatic. These four effects interact with each other to resist the onset and progression of cellular damage leading to the development of hepatitis, followed by cirrhosis and HCC. Moreover, it is important to note that artemisinins can play a role against $\mathrm{HCC}$ by antagonizing fibrogenesis at the end-stage of liver pathology and inhibit angiogenesis, invasion, and metastasis in the development of HCC. Additionally, artemisinin-induced autophagy, ferroptosis, and senescence of HSCs also constitute the mechanisms to treat liver diseases. Previous pharmacokinetic studies suggest that artemisinins are mainly metabolized by liver microsomes and can trigger auto-induction; thus, the half-life of artemisinin is short in vivo. Simultaneously, artemisinins affect the metabolism of other drugs by regulating enzymes related to metabolism. Some animal studies showed that certain doses of artemisinin produce toxic effects to varying degrees. Nevertheless, there are few toxic effects when artemisinins were used to treat malaria in humans. A possible reason for this is that smaller doses over longer periods are more toxic than larger doses over shorter periods. Therefore, this should be considered when artemisinin is used in the future.

Despite accumulating evidence for the application of artemisinins, their use as treatment for chronic hepatic disease in routine clinical practice is extremely limited. Due to the lack of randomized controlled clinical trials, the potential of artemisinins in the treatment of liver disease has not been well explored. The chemosensitization 
effect of artemisinins combined with chemotherapeutic agents requires further clarification. The evaluation of the therapeutic efficacy of artemisinins should be further standardized, especially in a NAFLD setting. To date, the treatment of chronic liver disease poses many difficult questions to be solved in clinical practice. Artemisinin, as a kind of safe and strong drug candidate, has provided a promising prospect for the treatment of chronic hepatic disease.

\begin{abstract}
Abbreviations
AFLD: Alcoholic fatty liver disease; NAFLD: Non-alcoholic fatty liver disease; HCC: Hepatocellular carcinoma; CCA: Cholangiocarcinoma; TCHM: Traditional chinese herbal medicine; ROS: Reactive oxygen species; ART: Artesunate; DHA: Dihydroartemisinin; ARM: Artemether; ARE: Arteether; NF-KB: Nuclear factor kappaB; AKT: Protein kinase B; TNF-a: Tumor necrosis factor-a; CDC25C: Cell division cycle 25 homolog C; E2F1: E2F transcription factor 1; CDK: Cyclindependent kinase; HSC: Hepatic stellate cell; PDGF: Platelet derived growth factor; NLRP3: NLR family pyrin domain containing 3; IL: Interleukin; IFN: Interferon; Bcl: B-cell lymphoma; Bax: BCl-2-associated X; Apaf-1: Apoptotic protease activating factor-1; PARP: Poly ADP-ribose polymerase; MDM2: Mouse double minute 2; STAT: Signal transducers and activators of transcription; GADD153: Growth-arrest-and-DNA-damage-inducible gene 153; Bim: $\mathrm{BCl}-2$ interaction mediator of cell death; Mcl-1: Myeloid cell leukemia-1; Bak: BCl-2 homologous antagonist/killer; MOMP: Mitochondrial outer membrane permeabilization; Puma: P53 upregulated modulator of apoptosis; EMT: Epithelial-to-mesenchymal transition; MMP: Matrix metalloproteinase; FN1: Fibronectin-1; ITGB1: $\beta 1$-Integrin; PI3K: Phosphoinositide 3-kinase; TIMP: Tissue inhibitor of metalloproteinases; ECM: Extracellular matrix; Cdc42: Cell division cycle 42; VEGF: Vascular endothelial growth factor; PIGF: Placental growth factor; TGF- $\beta R 1$ : Tumor growth factor- $\beta$ receptor 1; EGFR: Epidermal growth factor receptor; STUB1: STIP1 homology and U-box containing protein 1; IRP2: Iron regulatory protein 2; a-SMA: a-Smooth muscle actin; PPAR: Peroxisome proliferators-activated receptors; MAPK: Mitogen-activated protein kinase; mTOR: Mammalian target of rapamycin; ERK: Extracellular signal-regulated protein kinases; ADM: Doxorubicin; P-gp: P-glycoprotein; ULK1: Unc-like kinase 1; LC3: Light chain 3; p70S6K: P-ribosomal protein 56 kinase; 4EBP1: 4E binding protein 1; LC3B: Light chain 3 beta; SQSTM1: Sequestosome 1; IUGR: Intrauterine growth retardation; GSH: Glutathione; T-SOD: T-superoxide dismutase; MDA: Malondialdehyde; PC: Protein carbonyl; 8-OhdG: 8-Hydroxy-2'-deoxyguanosine; GSSG: Oxidized glutathione; I/R: Ischemia/Reperfusion; TLR4: Toll-like receptor 4; LPS: Lipopolysaccharide; MyD88: Myeloid differentiation primary response protein 88; Con A: Concanavalin A; AST: Aspartate transaminase; ALT: Alanine transaminase; LCA: Lithocholic acid; BDL: Bile duct ligation; AA: Artemisia annua leaf; HMGB1: High-mobility group box 1; COX-2: Cyclooxygenase-2; HFD: High-fat diet; JNK: C-Jun N-terminal kinase; ACC: Acetyl-CoA carboxylase; ChREBP: Carbohydrate-responsive element-binding protein; SREBP 1: Sterol regulatory element-binding protein 1; TG: Triglyceride; NIDDM: NAFLD/ non-insulin-dependent diabetes mellitus; TC: Total cholesterol; VLDLC: Very-low-density lipoprotein cholesterol; NEFA: Non-esterified fatty acid; TL: Total lipase; HL: Hepatic lipase; LPL: Lipoprotein lipase; AMPK: Adenosine 5'-monophosphate-activated protein kinase; MCP-1: Monocyte chemotactic protein-1; LDL-C: Low-density lipoprotein cholesterol; FXR: Farnesoid X receptor; ER: Endoplasmic reticulum; CHOP: C/EBP homologous protein; SCD1: Stearoyl-CoA-Desaturase 1; Fas: Factor related apoptosis; CPT-1a: Carnitine palmitoyltransferase 1a; GATA6: GATA binding protein 6; S1PR2: Sphingosine1-phosphate receptor 2; p-MYPT1: Phospho-myosin phosphatase target subunit 1; ROCK: Rho-associated kinase; MLCK: Myosin light chain kinase; p-MLC: Phospho-myosin light chain; C-Myc: Cellular-myelocytomatosis viral oncogene; NEDD4: Neural precursor cell expressed developmentally downregulated gene 4; ATT: Artemisitene; CYP: Cytochrome P450.
\end{abstract}

\section{Acknowledgements}

Not applicable.

\section{Authors' contributions}

YX conceptualization and original draft preparation; JH review and editing draft. Both authors read and approved the final manuscript.

\section{Funding}

This work was supported by the Independent Task of State Key Laboratory for Diagnosis and Treatment of Infectious Diseases.

\section{Availability of data and materials \\ Not applicable.}

\section{Declarations}

Ethics approval and consent to participate

Not applicable.

\section{Consent for publication}

Not applicable.

\section{Competing interests}

The authors declare that they have no competing interests.

Received: 29 May 2021 Accepted: 4 August 2021

Published online: 18 August 2021

\section{References}

1. Hardy T, Mann DA. Epigenetics in liver disease: from biology to therapeutics. Gut. 2016;65(11):1895-905.

2. Pimpin L, et al. Burden of liver disease in Europe: Epidemiology and analysis of risk factors to identify prevention policies. J Hepatol. 2018;69(3):718-35.

3. Wang FS, et al. The global burden of liver disease: the major impact of China. Hepatology. 2014;60(6):2099-108.

4. Grant DM. Detoxification pathways in the liver. J Inherit Metab Dis. 1991;14(4):421-30.

5. Sarin SK, et al. Liver diseases in the Asia-Pacific region: a Lancet Gastroenterology \& Hepatology Commission. Lancet Gastroenterol Hepatol. 2020;5(2):167-228.

6. Byrne CD, Targher G. NAFLD: a multisystem disease. J Hepatol. 2015;62(1 Suppl):S47-64.

7. Sreenivasmurthy SG, et al. Neurogenic traditional chinese medicine as a promising strategy for the treatment of Alzheimer's Disease. Int J Mol Sci. 2017;18:2

8. Luo $\mathrm{H}$, et al. Naturally occurring anti-cancer compounds: shining from Chinese herbal medicine. Chin Med. 2019;14:48.

9. Liu C, et al. Honeysuckle-derived microRNA2911 inhibits tumor growth by targeting TGF- $\beta 1$. Chin Med. 2021;16(1):49.

10. Luo E, et al. Treatment efficacy analysis of traditional Chinese medicine for novel coronavirus pneumonia (COVID-19): an empirical study from Wuhan, Hubei Province China. Chin Med. 2020;15:34.

11. Qiao O, et al. Cerebralcare Granule ${ }^{\circledR}$ enhances memantine hydrochloride efficacy in APP/PS1 mice by ameliorating amyloid pathology and cognitive functions. Chin Med. 2021;16(1):47.

12. Yang $L$, et al. Integrating metabolomic data with machine learning approach for discovery of Q-markers from Jinqi Jiangtang preparation against type 2 diabetes. Chin Med. 2021;16(1):30.

13. Federico A, Dallio M, Loguercio C. Silymarin/silybin and chronic liver disease: a marriage of many years. Molecules. 2017;22:2.

14. Zhang $\mathrm{Y}$, et al. A discovery of clinically approved formula fbrp for repositioning to treat $\mathrm{HCC}$ by inhibiting PI3K/AKT/NF-KB activation. Mol Ther Nucleic Acids. 2020;19:890-904.

15. Andrade RJ, et al. Drug-induced liver injury. Nat Rev Dis Primers. 2019;5(1):58.

16. van Agtmael MA, Eggelte TA, van Boxtel CJ. Artemisinin drugs in the treatment of malaria: from medicinal herb to registered medication. Trends Pharmacol Sci. 1999;20(5):199-205. 
17. Wong YK, et al. Artemisinin as an anticancer drug: Recent advances in target profiling and mechanisms of action. Med Res Rev. 2017;37(6):1492-517.

18. Lu F, et al. A brief history of artemisinin: Modes of action and mechanisms of resistance. Chin J Nat Med. 2019;17(5):331-6.

19. Ma N, et al. The birth of artemisinin. Pharmacol Ther. 2020;216:107658.

20. Martino $\mathrm{E}$, et al. Artemisinin and its derivatives; ancient tradition inspiring the latest therapeutic approaches against malaria. Future Med Chem. 2019;11(12):1443-59.

21. Tu Y. The development of the antimalarial drugs with new type of chemical structure-qinghaosu and dihydroqinghaosu. Southeast Asian J Trop Med Public Health. 2004;35(2):250-1.

22. Khanal P. Antimalarial and anticancer properties of artesunate and other artemisinins: current development. Monatsh Chem. 2021;1:1-14.

23. Konstat-Korzenny E, et al. Artemisinin and its synthetic derivatives as a possible therapy for cancer. Med Sci (Basel). 2018;6:1.

24. Karunajeewa H. Artemisinins: artemisinin, dihydroartemisinin, artemether and artesunate. Milestones Drug Ther. 2012:41:157-90.

25. Zyad A, et al. More insights into the pharmacological effects of artemisinin. Phytother Res. 2018;32(2):216-29.

26. Hien TT, et al. Orally formulated artemisinin in healthy fasting Vietnamese male subjects: a randomized, four-sequence, open-label, pharmacokinetic crossover study. Clin Ther. 2011;33(5):644-54.

27. Morris CA, et al. Review of the clinical pharmacokinetics of artesunate and its active metabolite dihydroartemisinin following intravenous, intramuscular, oral or rectal administration. Malar J. 2011;10:263.

28. Zhang $X G$, et al. A review of dihydroartemisinin as another gift from traditional Chinese medicine not only for malaria control but also for schistosomiasis control. Parasitol Res. 2014;113(5):1769-73.

29. Dai X, et al. Dihydroartemisinin: a potential natural anticancer drug. Int J Biol Sci. 2021;17(2):603-22

30. Raffetin A, et al. Use of artesunate in non-malarial indications. Med Mal Infect. 2018;48(4):238-49.

31. Meshnick SR, Taylor TE, Kamchonwongpaisan S. Artemisinin and the antimalarial endoperoxides: from herbal remedy to targeted chemotherapy. Microbiol Rev. 1996;60(2):301-15.

32. Cheong DHJ, et al. Anti-malarial drug, artemisinin and its derivatives for the treatment of respiratory diseases. Pharmacol Res. 2020;158:104901.

33. Yang J, et al. Advances in the research on the targets of anti-malaria actions of artemisinin. Pharmacol Ther. 2020;216:107697.

34. Miller LH, Su X. Artemisinin: discovery from the Chinese herbal garden. Cell. 2011;146(6):855-8.

35. Ho WE, et al. Artemisinins: pharmacological actions beyond anti-malarial. Pharmacol Ther. 2014;142(1):126-39.

36. Loo CS, et al. Artemisinin and its derivatives in treating protozoan infections beyond malaria. Pharmacol Res. 2017;117:192-217.

37. Efferth T. From ancient herb to modern drug: Artemisia annua and artemisinin for cancer therapy. Semin Cancer Biol. 2017:46:65-83.

38. Wang J, et al. Artemisinin directly targets malarial mitochondria through its specific mitochondrial activation. PLOS ONE. 2010;5(3):e9582

39. Efferth $\mathrm{T}$, et al. The antiviral activities of artemisinin and artesunate. Clin Infect Dis. 2008:47(6):804-11.

40. Eteng MU, et al. Biochemical and haematological evaluation of repeated dose exposure of male Wistar rats to an ethanolic extract of Artemisia annua. Phytother Res. 2013;27(4):602-9.

41. Li J, et al. Artemisinins Target GABA(A) receptor signaling and impair a cell identity. Cell. 2017;168(1-2):86-100.e15

42. Wu J, et al. Flavonoids from Aurantii Fructus Immaturus and Aurantii Fructus: promising phytomedicines for the treatment of liver diseases. Chin Med. 2020;15:89.

43. Li $\mathrm{X}$, et al. Evodiamine and rutaecarpine from Tetradium ruticarpum in the treatment of liver diseases. Phytomedicine. 2020;68:153180.

44. Li X, Sun R, Liu R. Natural products in licorice for the therapy of liver diseases: progress and future opportunities. Pharmacol Res. 2019:144:210-26.

45. Yang JY, et al. Pharmacological properties of baicalin on liver diseases: a narrative review. Pharmacol Rep. 2021. https://doi.org/10.1007/ s43440-021-00227-1.

46. Slezakova S, Ruda-Kucerova J. Anticancer activity of artemisinin and its derivatives. Anticancer Res. 2017;37(11):5995-6003.
47. Mancuso RI, Foglio MA, Saad ST. Artemisinin-type drugs for the treatment of hematological malignancies. Cancer Chemother Pharmacol. 2021:87(1):1-22.

48. von Hagens $C$, et al. Prospective open uncontrolled phase I study to define a well-tolerated dose of oral artesunate as add-on therapy in patients with metastatic breast cancer (ARTIC M33/2). Breast Cancer Res Treat. 2017:164(2):359-69.

49. Greenshields AL, Shepherd TG, Hoskin DW. Contribution of reactive oxygen species to ovarian cancer cell growth arrest and killing by the anti-malarial drug artesunate. Mol Carcinog. 2017;56(1):75-93.

50. Zhang $C Z$, et al. Dihydroartemisinin exhibits antitumor activity toward hepatocellular carcinoma in vitro and in vivo. Biochem Pharmacol. 2012;83(9):1278-89.

51. Hou J, et al. Experimental therapy of hepatoma with artemisinin and its derivatives: in vitro and in vivo activity, chemosensitization, and mechanisms of action. Clin Cancer Res. 2008;14(17):5519-30.

52. Chen Q, et al. Dihydroartemisinin alleviates bile duct ligation-induced liver fibrosis and hepatic stellate cell activation by interfering with the PDGF- $\beta R / E R K$ signaling pathway. Int Immunopharmacol. 2016:34:250-8.

53. Yin $\mathrm{S}$, et al. Antimalarial agent artesunate induces G0/G1 cell cycle arrest and apoptosis via increasing intracellular ROS levels in normal liver cells. Hum Exp Toxicol. 2020;39(12):1681-9.

54. Zhang Z, et al. ROS-JNK1/2-dependent activation of autophagy is required for the induction of anti-inflammatory effect of dihydroartemisinin in liver fibrosis. Free Radic Biol Med. 2016;101:272-83.

55. Zou J, et al. Dihydroartemisinin inhibits HepG2.2.15 proliferation by inducing cellular senescence and autophagy. BMB Rep. 2019:52(8):520-4.

56. Shi $X$, et al. Dihydroartemisinin, an antimalarial drug, induces absent in melanoma 2 inflammasome activation and autophagy in human hepatocellular carcinoma HepG2215 cells. Phytother Res. 2019;33(5):1413-25.

57. $\mathrm{Hu} \mathrm{H}$, et al. Dihydroartemisinin/miR-29b combination therapy increases the pro-apoptotic effect of dihydroartemisinin on cholangiocarcinoma cell lines by regulating Mcl-1 expression. Adv Clin Exp Med. 2020;29(8):911-9.

58. Gao X, et al. Dihydroartemisinin induces endoplasmic reticulum stress-mediated apoptosis in HepG2 human hepatoma cells. Tumori. 2011;97(6):771-80.

59. Wu R, et al. Semi-synthetic product dihydroartemisinin inhibited fibronectin- 1 and integrin- $\beta 1$ and interfered with the migration of HCCLM6 cells via PI3K-AKT pathway. Biotechnol Lett. 2020;42(6):917-26.

60. Li Y, et al. Artemisinin suppresses hepatocellular carcinoma cell growth, migration and invasion by targeting cellular bioenergetics and HippoYAP signaling. Arch Toxicol. 2019;93(11):3367-83.

61. Zhai JM, et al. Sorafenib enhances the chemotherapeutic efficacy of S-1 against hepatocellular carcinoma through downregulation of transcription factor E2F-1. Cancer Chemother Pharmacol. 2013;71(5):1255-64.

62. Blazquez $A G$, et al. Novel artemisinin derivatives with potential usefulness against liver/colon cancer and viral hepatitis. Bioorg Med Chem. 2013;21(14):4432-41.

63. Longxi $\mathrm{P}$, et al. Expression of $\mathrm{p} 53$ in the effects of artesunate on induction of apoptosis and inhibition of proliferation in rat primary hepatic stellate cells. PLOS ONE. 2011;6(10):e26500.

64. LV J, et al. Artesunate may inhibit liver fibrosis via the FAK/Akt/ $\beta$-catenin pathway in LX-2 cells. BMC Pharmacol Toxicol. 2018;19(1):64.

65. Deng XR, et al. Holotransferrin enhances selective anticancer activity of artemisinin against human hepatocellular carcinoma cells. J Huazhong Univ Sci Technolog Med Sci. 2013;33(6):862-5.

66. Zhang $Z$, et al. Antisense therapy targeting MDM2 oncogene in prostate cancer: effects on proliferation, apoptosis, multiple gene expression, and chemotherapy. Proc Natl Acad Sci USA. 2003;100(20):11636-41.

67. Bykov VJ, Wiman KG. Novel cancer therapy by reactivation of the p53 apoptosis pathway. Ann Med. 2003;35(7):458-65.

68. Zhang Z, et al. Oncogenes as novel targets for cancer therapy (part IV): regulators of the cell cycle and apoptosis. Am J Pharmacogenomics. 2005;5(6):397-407.

69. Qian P, et al. Artesunate enhances $\gamma \delta$ T-cell-mediated antitumor activity through augmenting $\gamma \delta$ T-cell function and reversing 
immune escape of HepG2 cells. Immunopharmacol Immunotoxicol. 2018;40(2):107-16.

70. Ilamathi M, Santhosh S, Sivaramakrishnan V. Artesunate as an anticancer agent targets stat-3 and favorably suppresses hepatocellular carcinoma. Curr Top Med Chem. 2016;16(22):2453-63.

71. Huang TE, et al. Evaluation of the Anticancer Activity of a Bile AcidDihydroartemisinin Hybrid Ursodeoxycholic-Dihydroartemisinin in Hepatocellular Carcinoma Cells. Front Pharmacol. 2020;11:599067.

72. Im E, et al. Dihydroartemisinin induced caspase-dependent apoptosis through inhibiting the specificity protein 1 pathway in hepatocellular carcinoma SK-Hep-1 cells. Life Sci. 2018;192:286-92.

73. Qin $\mathrm{G}$, et al. Dihydroartemisinin induces apoptosis preferentially via a Bim-mediated intrinsic pathway in hepatocarcinoma cells. Apoptosis. 2015;20(8):1072-86.

74. Pang $Y$, et al. Artesunate induces ROS-dependent apoptosis via a Baxmediated intrinsic pathway in Huh-7 and Hep3B cells. Exp Cell Res. 2016;347(2):251-60.

75. Qin G, et al. Artesunate induces apoptosis via a ROS-independent and Bax-mediated intrinsic pathway in HepG2 cells. Exp Cell Res. 2015;336(2):308-17.

76. Yao X, et al. Synergistic antitumor activity of sorafenib and artesunate in hepatocellular carcinoma cells. Acta Pharmacol Sin. 2020;41(12):1609-20.

77. $\mathrm{Hu} \mathrm{H}$, et al. Upregulation of the MCL-1S protein variant following dihydroartemisinin treatment induces apoptosis in cholangiocarcinoma cells. Oncol Lett. 2015;10(6):3545-50.

78. Kalluri R, Weinberg RA. The basics of epithelial-mesenchymal transition. J Clin Invest. 2009;1 19(6):1420-8.

79. Beuran $\mathrm{M}$, et al. The epithelial to mesenchymal transition in pancreatic cancer: a systematic review. Pancreatology. 2015;15(3):217-25.

80. Aiello NM, Kang Y. Context-dependent EMT programs in cancer metastasis. J Exp Med. 2019;216(5):1016-26.

81. Jing $W$, et al. Dependence of artesunate on long noncoding RNARP11 to inhibit epithelial-mesenchymal transition of hepatocellular carcinoma. J Cell Biochem. 2019;120(4):6026-34.

82. Weifeng $\mathrm{T}$, et al. Artemisinin inhibits in vitro and in vivo invasion and metastasis of human hepatocellular carcinoma cells. Phytomedicine. 2011;18(2-3):158-62.

83. Vandewynckel YP, et al. Therapeutic effects of artesunate in hepatocellular carcinoma: repurposing an ancient antimalarial agent. Eur J Gastroenterol Hepatol. 2014;26(8):861-70.

84. $\mathrm{Li} \mathrm{H}$, et al. Artesunate and sorafenib: Combinatorial inhibition of liver cancer cell growth. Oncol Lett. 2019;18(5):4735-43.

85. Friedman SL. Hepatic stellate cells: protean, multifunctional, and enigmatic cells of the liver. Physiol Rev. 2008;88(1):125-72.

86. Barry AE, et al. Hepatic Stellate Cells and Hepatocarcinogenesis. Front Cell Dev Biol. 2020;8:709.

87. Kong Z, Liu R, Cheng Y. Artesunate alleviates liver fibrosis by regulating ferroptosis signaling pathway. Biomed Pharmacother. 2019;109:2043-53.

88. Wang $L$, et al. P53-dependent induction of ferroptosis is required for artemether to alleviate carbon tetrachloride-induced liver fibrosis and hepatic stellate cell activation. IUBMB Life. 2019;71(1):45-56.

89. Li Y, et al. Iron regulatory protein 2 is required for artemether -mediated anti-hepatic fibrosis through ferroptosis pathway. Free Radic Biol Med. 2020;160:845-59.

90. Ruan JJ, Du Y. Effects of artesunate on the inhibition of hepatic fibrosis through ceramide synthase-ceramide pathway. Zhongguo Ying Yong Sheng Li Xue Za Zhi. 2020;36(3):279-82.

91. Shen S, Luo J, Ye J. Artesunate alleviates schistosomiasis-induced liver fibrosis by downregulation of mitochondrial complex I subunit NDUFB8 and complex III subunit UQCRC2 in hepatic stellate cells. Acta Trop. 2020;2020:105781

92. Shinoda $\mathrm{M}$, et al. Long-term complete response of advanced hepatocellular carcinoma treated with multidisciplinary therapy including reduced dose of sorafenib: case report and review of the literature. World J Surg Oncol. 2015;13:144.

93. Jing W, et al. Artesunate promotes sensitivity to sorafenib in hepatocellular carcinoma. Biochem Biophys Res Commun. 2019;519(1):41-5.
94. Chan KT, Lung ML. Mutant p53 expression enhances drug resistance in a hepatocellular carcinoma cell line. Cancer Chemother Pharmacol. 2004;53(6):519-26.

95. Yang Y, et al. Dihydroartemisinin Sensitizes Mutant p53 (R248Q)Expressing Hepatocellular Carcinoma Cells to Doxorubicin by Inhibiting P-gp Expression. Biomed Res Int. 2019;2019:8207056.

96. Rautou PE, et al. Autophagy in liver diseases. J Hepatol. 2010;53(6):1123-34.

97. Chun Y, Kim J. Autophagy: an essential degradation program for cellular homeostasis and life. Cells. 2018;7:12.

98. Huang F, Wang BR, Wang YG. Role of autophagy in tumorigenesis, metastasis, targeted therapy and drug resistance of hepatocellular carcinoma. World J Gastroenterol. 2018;24(41):4643-51.

99. Zhang Z, et al. Interaction between autophagy and senescence is required for dihydroartemisinin to alleviate liver fibrosis. Cell Death Dis. 2017;8(6):e2886.

100. Jiang P, Mizushima N. LC3- and p62-based biochemical methods for the analysis of autophagy progression in mammalian cells. Methods. 2015;75:13-8.

101. Allaire $\mathrm{M}$, et al. Autophagy in liver diseases: Time for translation? J Hepatol. 2019;70(5):985-98.

102. Biri A, et al. Role of oxidative stress in intrauterine growth restriction. Gynecol Obstet Invest. 2007;64(4):187-92.

103. Liu J, et al. Effect of folic acid supplementation on hepatic antioxidant function and mitochondrial-related gene expression in weanling intrauterine growth retarded piglets. Livest Sci. 2012;146(2):123-32.

104. Zhao Y, et al. Dietary Dihydroartemisinin Supplementation Attenuates Hepatic Oxidative Damage of Weaned Piglets with Intrauterine Growth Retardation through the Nrf2/ARE Signaling Pathway. Animals (Basel). 2019;9:12.

105. Ghoneim ME, et al. The interrupted cross-talk of inflammatory and oxidative stress trajectories signifies the effect of artesunate against hepatic ischemia/reperfusion-induced inflammasomopathy. Toxicol Appl Pharmacol. 2020;409:115309.

106. Su Q, et al. Role of TLR4/MyD88/NF-KB signaling pathway in coronary microembolization-induced myocardial injury prevented and treated with nicorandil. Biomed Pharmacother. 2018;106:776-84.

107. Lin RS, et al. Endotoxemia in patients with chronic liver diseases: relationship to severity of liver diseases, presence of esophageal varices, and hyperdynamic circulation. J Hepatol. 1995;22(2):165-72.

108. Lai $L$, et al. Artesunate alleviates hepatic fibrosis induced by multiple pathogenic factors and inflammation through the inhibition of LPS/TLR4/NF-KB signaling pathway in rats. Eur J Pharmacol. 2015;765:234-41.

109. Zhao $X$, et al. Antimalarial agent artesunate protects Concanavalin A-induced autoimmune hepatitis in mice by inhibiting inflammatory responses. Chem Biol Interact. 2017;274:116-23.

110. Alkhedaide $A Q$, et al. Preventive effect of artemisinin extract against cholestasis induced via lithocholic acid exposure. Biosci Rep. 2018;38:6.

111. Chen Q, et al. Dihydroartemisinin prevents liver fibrosis in bile duct ligated rats by inducing hepatic stellate cell apoptosis through modulating the PI3K/Akt pathway. IUBMB Life. 2016;68(3):220-31.

112. He J, et al. Dietary Tributyrin Supplementation Attenuates Insulin Resistance and Abnormal Lipid Metabolism in Suckling Piglets with Intrauterine Growth Retardation. PLoS ONE. 2015;10(8):e0136848.

113. Zhao Y, et al. Effects of dietary dihydroartemisinin supplementation on growth performance, hepatic inflammation, and lipid metabolism in weaned piglets with intrauterine growth retardation. Anim Sci J. 2020;91(1):e13363.

114. Kim KE, et al. Artemisia annua Leaf Extract Attenuates Hepatic Steatosis and Inflammation in High-Fat Diet-Fed Mice. J Med Food. 2016;19(3):290-9.

115. Lodder J, et al. Macrophage autophagy protects against liver fibrosis in mice. Autophagy. 2015;11(8):1280-92.

116. Mallat A, et al. Autophagy: a multifaceted partner in liver fibrosis. Biomed Res Int. 2014:2014:869390.

117. Suresh D, Srinivas AN, Kumar DP. Etiology of hepatocellular carcinoma: special focus on fatty liver disease. Front Oncol. 2020;10:601710.

118. Gao, Q., et al., Artemisinin mimics nitric oxide to reduce adipose weight by targeting mitochondrial complexes. bioRxiv. 2017;p. 157396. 
119. Fu W, et al. Artemether regulates metaflammation to improve glycolipid metabolism in db/db mice. Diabetes Metab Syndr Obes. 2020;13:1703-13.

120. $\mathrm{Xu} \mathrm{W}$, et al. Dihydroartemisinin protects against alcoholic liver injury through alleviating hepatocyte steatosis in a farnesoid $X$ receptordependent manner. Toxicol Appl Pharmacol. 2017;315:23-34.

121. Shimano H, Sato R. SREBP-regulated lipid metabolism: convergent physiology - divergent pathophysiology. Nat Rev Endocrinol. 2017;13(12):710-30

122. Chen $X$, et al. Dihydroartemisinin inhibits ER stress-mediated mitochondrial pathway to attenuate hepatocyte lipoapoptosis via blocking the activation of the PI3K/Akt pathway. Biomed Pharmacother. 2018:97:975-84

123. Chen $\mathrm{X}$, et al. Dihydroartemisinin attenuates alcoholic fatty liver through regulation of lipin-1 signaling. IUBMB Life. 2019;71(11):1740-50.

124. Hernandez-Gea V, Friedman SL. Pathogenesis of liver fibrosis. Annu Rev Pathol. 2011;6:425-56.

125. Lee YA, Wallace MC, Friedman SL. Pathobiology of liver fibrosis: a translational success story. Gut. 2015:64(5):830-41.

126. Xu Y, et al. Artesunate ameliorates hepatic fibrosis induced by bovine serum albumin in rats through regulating matrix metalloproteinases. Eur J Pharmacol. 2014;744:1-9.

127. Xu W, et al. Dihydroartemisinin counteracts fibrotic portal hypertension via farnesoid $X$ receptor-dependent inhibition of hepatic stellate cell contraction. FEBS J. 2017;284(1):114-33.

128. Torre LA, et al. Global cancer statistics, 2012. CA Cancer J Clin 2015;65(2):87-108.

129. Zhang $C Z$, et al. Histone deacetylase inhibitors facilitate dihydroartemisinin-induced apoptosis in liver cancer in vitro and in vivo. PLOS ONE. 2012;7(6):e39870.

130. Lokau J, et al. Jak-Stat signaling induced by interleukin-6 family cytokines in hepatocellular carcinoma. Cancers (Basel). 2019;11:11.

131. Ilamathi $M$, et al. Artesunate obliterates experimental hepatocellular carcinoma in rats through suppression of IL-6-JAK-STAT signalling. Biomed Pharmacother. 2016;82:72-9.

132. Chen J, et al. Artemisitene suppresses tumorigenesis by inducing DNA damage through deregulating c-Myc-topoisomerase pathway. Oncogene. 2018;37(37):5079-87.

133. Manikandan P, Nagini S. Cytochrome P450 structure, function and clinical significance: a review. Curr Drug Targets. 2018;19(1):38-54.

134. Kerb R, et al. Pharmacogenetics of antimalarial drugs: effect on metabolism and transport. Lancet Infect Dis. 2009;9(12):760-74.

135. Chhonker YS, et al. Assessment of clinical pharmacokinetic drug-drug interaction of antimalarial drugs a/ $\beta$-arteether and sulfadoxinepyrimethamine. Antimicrob Agents Chemother. 2017;61:9.

136. Elewa $\mathrm{H}$, Wilby KJ. A review of pharmacogenetics of antimalarials and associated clinical implications. Eur J Drug Metab Pharmacokinet. 2017:42(5):745-56.

137. Simonsson US, et al. Artemisinin autoinduction is caused by involvement of cytochrome P450 2B6 but not 2C9. Clin Pharmacol Ther. 2003;74(1):32-43.

138. Chai $L$, et al. Auto-induction of intestinal first-pass effect related timedependent pharmacokinetics of artemisinin rather than dihydroartemisinin. J Pharm Sci. 2021;110(1):458-66.
139. Sukhija M, Medhi B, Pandhi P. Effects of artemisinin, artemether, arteether on the pharmacokinetics of carbamazepine. Pharmacology. 2006;76(3):110-6.

140. Elsherbiny DA, et al. A model based assessment of the CYP2B6 and CYP2C19 inductive properties by artemisinin antimalarials: implications for combination regimens. J Pharmacokinet Pharmacodyn. 2008;35(2):203-17.

141. Bapiro TE, et al. Artemisinin and thiabendazole are potent inhibitors of cytochrome P450 1A2 (CYP1A2) activity in humans. Eur J Clin Pharmacol. 2005;61(10):755-61.

142. Ribeiro IR, Olliaro P. Safety of artemisinin and its derivatives. A review of published and unpublished clinical trials. Med Trop (Mars). 1998;58(3 Suppl):50-3.

143. Deeken JF, et al. A phase I study of intravenous artesunate in patients with advanced solid tumor malignancies. Cancer Chemother Pharmacol. 2018;81(3):587-96.

144. Ruperti-Repilado FJ, et al. Danger of herbal tea: a case of acute cholestatic hepatitis due to Artemisia annua Tea. Front Med (Lausanne). 2019;6:221.

145. Kumar S. Cholestatic liver injury secondary to artemisinin. Hepatology. 2015;62(3):973-4

146. Efferth $\mathrm{T}$, et al. Hepatotoxicity by combination treatment of temozolomide, artesunate and Chinese herbs in a glioblastoma multiforme patient: case report review of the literature. Arch Toxicol. 2017;91(4):1833-46.

147. Uhl M, Schwab S, Efferth T. Fatal liver and bone marrow toxicity by combination treatment of dichloroacetate and artesunate in a glioblastoma multiforme patient: case report and review of the literature. Front Oncol. 2016;6:204

148. Efferth T, Kaina B. Toxicity of the antimalarial artemisinin and its dervatives. Crit Rev Toxicol. 2010:40(5):405-21.

149. Efferth T. Cancer combination therapies with artemisinin-type drugs. Biochem Pharmacol. 2017;139:56-70.

150. Abba ML, et al. Prevention of carcinogenesis and metastasis by Artemisinin-type drugs. Cancer Lett. 2018;429:11-8.

151. Bai L, et al. Immunosuppressive effect of artemisinin and hydroxychloroquine combination therapy on IgA nephropathy via regulating the differentiation of CD4+ T cell subsets in rats. Int Immunopharmacol. 2019;70:313-23.

152. Hou L, Huang $\mathrm{H}$. Immune suppressive properties of artemisinin family drugs. Pharmacol Ther. 2016;166:123-7.

\section{Publisher's Note}

Springer Nature remains neutral with regard to jurisdictional claims in published maps and institutional affiliations.

Ready to submit your research? Choose BMC and benefit from

- fast, convenient online submission

- thorough peer review by experienced researchers in your field

- rapid publication on acceptance

- support for research data, including large and complex data types

- gold Open Access which fosters wider collaboration and increased citations

- maximum visibility for your research: over $100 \mathrm{M}$ website views per year

At $\mathrm{BMC}$, research is always in progress.

Learn more biomedcentral.com/submissions 